\title{
When is "Too Much" Inequality Not Enough? The Selection of Israeli Emigrants
}

\author{
Eric D. Gould and Omer Moav*
}

September 21, 2008

\begin{abstract}
This paper examines the effect of inequality on the incentives to emigrate according to a person's observable and unobservable skills. Borjas (1987) shows that higher skilled individuals are more likely to emigrate than lower skilled individuals when the returns to skill are higher in a potential foreign destination. Building on this framework, we develop a model which shows that this prediction holds for observable skills like education which are "general" in the sense of being easily transferable to another country. However, we show that the relationship between unobservable skills and the probability of emigrating is an inverse U-shape - since unobservable skills are a mixture of "general skills" and "country-specific skills" which are not easily transferable. We examine the predictions of our model with a unique data set containing information on who emigrates from Israel between 1995 and 2004, combined with a full set of demographic and labor market variables for both movers and stayers in 1995. By exploiting differences between Israel and the United States in the returns to observable (education) and unobservable skills across different sectors (industries and occupations), we find strong evidence that a lower return to unobservable skills in Israel versus the US entices higher ability Israelis to leave the country. Also, we find that virtually the entire positive relationship between education and the rate of emigration would be eliminated if the returns to education were increased in Israel to US levels within each industry. Overall, the results strongly support our model and the importance of differentiating between general and "country-specific" skills in the analysis of immigrant selection.
\end{abstract}

*Affiliations for the authors are: Eric Gould - Hebrew University, Shalem Center, CEPR, and IZA; Omer Moav - Hebrew University, University of London, Royal Holloway, Shalem Center, and CEPR; Email addresses of the authors (respectively): eric.gould@huji.ac.il, msmoav@huji.ac.il. We thank Daniel Hamermesh for valuable comments, as well as seminar participants at the Hebrew University, Tel Aviv University, Bar Ilan University, and the Labor Studies Workshop at the NBER Summer Institute 2008. We thank Shalva Zonenashvili for providing excellent research assistance. 


\section{Introduction}

There are perhaps only two issues that Israeli politicians from across the political spectrum agree upon: (1) there is too much income inequality in Israel; and (2) Israel is suffering from a "Brain Drain." It is in fact true that Israel ranks high in international comparisons of income inequality. For example, Brandolini and Smeeding (2008) examine 24 developed countries and find that only the United States has a higher ratio of personal disposable income between the 90th and 10th percentiles. In addition, recent evidence is emerging that Israel suffers from a high rate of emigration of highly skilled workers (Gould and Moav (2007) and Ben-David (2008)). However, this paper analyzes the possibility that it may be a contradiction to think that both of these perceived problems can be mitigated simultaneously. Specifically, we examine the general idea that the existence of a brain drain is a sign that inequality is too low, a prospect which is well-founded in economic theory.

Building on the classic model of occupational choice by Roy (1951), a seminal paper by Borjas (1987) develops a model of an individual's decision to emigrate which is based on the comparison of his wages in his "source" country versus a potential "host" country. ${ }^{1}$ A higher wage gap in favor of the host country increases the probability of emigrating. However, the model also predicts that higher skilled workers are more likely than lessskilled workers to leave a country with a low return to skill and move to a country with a higher return to skill. The reverse is also true - a lower skilled individual is more likely than a higher skilled worker to leave a country with a high return to skill and move to a country with a lower return to skill. These predictions are quite intuitive - higher skilled individuals benefit from higher inequality since they are at the top of the distribution, while lower skilled individuals benefit from lower inequality since they are at the bottom of the distribution. Therefore, a more compressed wage distribution encourages higher skilled individuals to leave ("positive selection"), while a more dispersed wage distribution entices lower skilled individuals to leave ("negative selection"). Thus, a "positive selection" of emigrants is a sign that inequality is low, and attempts to lower it even further may exacerbate the phenomenon.

In this paper, we extend the model by arguing that some skills are "general" in the sense that they can easily be transported to a foreign country, and some skills are "country-specific" in nature, and therefore, are not easily transferred to another country.

\footnotetext{
${ }^{1}$ Sjaastad (1962) also models the decision to emigrate based on the wage gain net of migration costs.
} 
Education is an example of a "general skill" which is likely to be rewarded in any country, while examples of "country-specific" skills include personal connections, local knowledge of the product and labor markets, language-specific communication skills, legal knowledge of the local environment, licenses which are country-specific, rents from union membership, firm-specific skills, and certain instances of luck (being at the right place at the right time).

After distinguishing between the two types of skills, our model shows that a higher return in a foreign country to an observable skill like education (which is considered a general skill) will produce "positive selection" in terms of the education levels of those that choose to emigrate. This prediction is similar to Borjas $(1987,1991,1999)$. However, the relationship between unobservable skills (unobservable to the econometrician) and the probability of emigration is not as straightforward - since unobservable skills are a mixture of general and country-specific skills. As a result, the relationship between emigrating and unobservable skill is shown to be an inverse $u$-shape. The intuition is fairly straightforward - a higher return to unobservable general skills in a foreign country implies that the benefits of emigration increase with the a person's level of unobservable general skill, but a higher level of unobserved country-specific skill raises the costs of emigration, since these skills will be rendered obsolete. Therefore, a larger amount of unobserved general skill relative to country-specific skill raises the probability that a person emigrates. Furthermore, a larger proportion of individuals have a high ratio of general to country-specific skills in the middle of the distribution than in the tails. This is due to the fact that those at the bottom of the unobservable skill distribution have very little of both types of skills, while those at the top have high levels of both. In contrast, individuals located in the middle of the distribution may have a high level of general or country-specific skills, but are unlikely to have high levels of both (or else they would be at the top of the distribution). As a result, individuals are more likely to have a high level of unobservable general skills versus country-specific skills if they are in the middle of the distribution rather than the tails. Therefore, the model predicts that emigration rates increase with unobservable skill and then decrease.

Furthermore, the model shows that for both observable and unobservable skills, an increase in the return to that skill in the target country relative to the home country will make the selection of emigrants more positive. That is, although the relationship between emigration and education is positive while the relationship between emigration and unobservable skill is u-shaped, an increase in the return to either skill abroad shifts the curve in a way that makes the selection of emigrants more positive. This finding 
highlights the idea that simply looking at the relationship between skill and emigration may not be a good test of the Borjas model, since many factors may influence the shape of the overall curve. The main forces of the Borjas model may still be relevant if an increase in the relative return to skill abroad shifts the curve so that emigrants are more positively selected, while keeping the overall shape of the curve intact.

Empirically analyzing selection in terms of observable and unobservable skills is made possible by exploiting a unique data set which includes the demographic and labor force characteristics of a random sample of Israelis in 1995, combined with an indicator for whether the respondent decided to emigrate as of 2004. This data set is a rare opportunity to examine the selection of emigrants using information on the emigrants before they move. ${ }^{2}$ This type of information is critical, since estimating the selection of emigrants necessarily entails a comparison of the characteristics of emigrants to those that chose not to move.

A simple analysis of our data, combined with a comparison of the wage distribution of Israel versus the United States, supports the main predictions of our model. Specifically, we show that the probability of emigrating increases with education. This is consistent with the predictions of the model, since education is a general skill and the return to education in Israel is much lower than the United States (0.071 versus 0.100). Therefore, higher educated Israelis are more likely to move in order to benefit from the higher return to this type of general skill. Furthermore, the data show that the probability of emigrating increases and then decreases with wages or residual wages (controlling for education, experience, etc.) This inverse u-shaped pattern is consistent with the model's predictions regarding the emigration rate of individuals according to their unobserved skills - which are composed of both general and country-specific components.

Of course, these broad patterns could be the product of other factors at work, rather than the forces emphasized in the model. For example, US immigration policy is likely to produce positive selection in terms of education, since education is observable to immigration authorities. Therefore, in order to test the implications of the model further, we exploit variation across different sectors (industries and occupations) in the differences between Israel and the United States in the returns to observable (education) and unobservable skills. It is important to note that we do not assume that all Israeli emigrants

\footnotetext{
${ }^{2}$ Chiquiar and Hanson (2005) write on page 240: "Largely missing in the discussion of U.S. immigration is evidence from source countries. Surprisingly, there is little work on how the skills of immigrants compare to the skills of nonmigrating individuals in countries of origin. Such data are essential to evaluate the nature of migrant selection."
} 
move to the US (although we show that most of them do), nor do we assume that they do not change their industry or occupation. Rather, the empirical strategy is to estimate to what extent Israelis consider these factors, and whether they do so in a way that is consistent with the model.

Our findings strongly suggest that this is indeed the case: a lower return to unobservable skills in Israel versus the US entices higher ability Israelis to leave the country. Also, we find that emigrants are more positively selected in terms of their education in industries with a lower relative return to education in Israel versus the US. In other words, a higher return to skills abroad shifts the curve in a way that increases the positive selection of emigrants in terms of observable or unobservable skills, while leaving intact the general shape of the relationship. As a result, this paper is the first to show that variation in the relative returns to skill (observable and unobservable) between the source country and the host country affects the selectivity of emigrants in a manner which is consistent with the Borjas model.

The coefficient estimates are not only statistically significant, but also large in magnitude. For example, the estimates imply that the positive relationship between emigration and education would be completely flattened if the returns to education in each industry were equal in Israel and the United States. Although the inverse u-shape relationship between unobserved skill and emigration cannot be eliminated with changes in the returns to unobserved skill, rather small changes in the return to unobserved skill are shown to produce significant shifts in the curve towards higher or lower levels of positive selection. Overall, the results strongly support the predictions of the model and the importance of differentiating between general and "country-specific" skills in the analysis of immigrant selection.

Although no other paper has examined the selection of emigrants in terms of observable and unobservable skills to the extent that we do, there are several papers examining the main prediction by Roy (1951) and Borjas (1987) that a higher return to skill in the source country should produce negative selection, while a higher return to skill in the host country should produce positive selection. Most of this literature examines the selection of Mexican immigrants, which according to the basic model, should be negatively selected on education since the return to education is higher in Mexico than the United States. Chiquiar and Hanson (2005) find evidence against the "negative selection" hypothesis for Mexican immigrants to the United States. ${ }^{3}$ Instead, they find that Mexican immigrants to

\footnotetext{
${ }^{3}$ Orrenius and Zavodny (2005) find similar results for illegal immigrants from Mexico. However, Ibar-
} 
the US come from the middle of the education distribution, which they explain by adding migration costs which decline with education to the model. ${ }^{4}$ As a result, Mexican workers at the bottom of the distribution are less likely to move due to their higher costs of moving, while those at the top of the distribution are less likely to move due to the higher returns to education in Mexico. In contrast, our results regarding selection on education are consistent with the basic model with or without the assumption that migration costs decline with education, and this additional assumption cannot help to explain the inverse $\mathrm{u}$-shaped pattern we see regarding selection on unobservables. The reason for this is that the return to unobservable skill is higher in the US versus Israel, whereas it was higher in Mexico versus the US for Chiquiar and Hanson (2005). Therefore, their augmented model cannot explain the $\mathrm{u}$-shaped pattern we observe in the data, thus underscoring the theoretical contribution of distinguishing between "general" and "country-specific" skills in our model.

The literature on the selection of emigrants from countries other than Mexico include Borjas (1987), who uses data on U.S. immigrants from 41 countries in the 1970 and 1980 U.S. Censuses and finds weak evidence that the source country's income inequality is negatively related to immigrant wages. Cobb-Clark (1993) finds similar results for female immigrants. Feliciano (2005) examines 32 immigrant groups in the United States, and finds that all but one group (immigrants from Puerto Rico) are positively selected in terms of education. However, Feliciano (2005) finds an insignificant relationship between inequality and the degree of positive selection from the source country. Grogger and Hanson (2008) examine the sorting of immigrants to 15 OECD countries from 102 source countries and find that immigrants in host countries are positively selected in relation to the source country when the education gap in wages between the host and source countries increases. However, when the education wage gap is measured in logs, they find evidence in favor of negative selection when the return to education is higher in the source country. Belot and Hatton (2008) examine immigrants in 29 OECD countries from 80 source countries and find little evidence in favor of the main prediction in Borjas (1987). Only after considering

raran and Lubotsky (2005) argue that Mexican immigrants are negatively selected, and consistent with the Roy (1951) and Borjas (1987), the degree of negative selection increases from Mexican counties with a higher return to skill. McKenzie and Rapoport (2007) show that the selection of Mexican immigrants becomes more negative from areas in Mexico which have lower overall migration costs (i.e. stronger migration networks).

${ }^{4}$ They argue that migration costs decline with education due to the effect of education on the ability to overcome bureaucratic requirements, the lower time costs required to earn enough money to pay the fixed-costs of moving, and fewer credit constraints on educated individuals. Chiswick (1999) also argues that moving costs decline with education, which tends to produce positive selection in emigrants. 
the poverty constraints in poor countries do they find evidence in support of Borjas (1987).

Overall, the evidence across countries displays a general pattern where highly educated individuals leave less developed countries with high returns to education and move to developed countries with lower returns to education. ${ }^{5}$ This pattern is not consistent with the predictions of the basic model in Borjas (1987). There may be many confounding factors in this type of empirical analysis, since there is large variation across countries in many factors which may influence the size and direction of the selection - such as language barriers, proximity, moving costs, immigration policy, visa requirements, etc. This may be one reason why the evidence in favor of the Borjas (1987) model is stronger in studies looking at internal migration (Borjas, Bronars, and Trejo (1992)). Our study is not affected by cross-country differences in factors which influence the level and selection of emigrants, since we analyze selection based on sectors within one country. As such, our main contribution is to show that there may be a non-monotonic relationship between emigration and skill based on many other factors, but the basic premise of the Borjas model may still be relevant - an increase in inequality abroad shifts the curve in a way that intensifies the level of positive selection, while keeping the overall shape of the curve intact. Moreover, we examine emigrant selection based on education and unobservable skill (residual wages), and not just on education which is the dimension analyzed in the studies mentioned above. As such, this paper is the first to examine the selection of emigrants in terms of observable and unobservable skills by exploiting variation in the returns to observable and unobservable skills between the source and host countries.

\section{The Data}

The analysis uses a unique data set composed of the 1995 Israeli Census merged with an indicator for whether each respondent left the country or not as of 2002 and as of 2004 . (We also received an indicator for whether the person died by 2002 or 2004.) If the person is considered a "mover" (a person who has left Israel), then the data set contains variables indicating the month and year when this person is considered to have left the country permanently.

Defining who is an emigrant is not straightforward. Many individuals travel abroad intending to stay for only a short period of time, but gradually their stay becomes permanent. Others may intend to leave forever but change their mind. As a result, any

\footnotetext{
${ }^{5}$ Rosenzweig (2006) finds that students from low wage countries migrate to developed countries in order to study as a way of obtaining a high wage job.
} 
definition of a "mover" is somewhat arbitrary. In our analysis, we use the official definition used by the Israel Central Bureau of Statistics, which considers any individual as a "mover" if he/she left the country for at least a full year. ${ }^{6}$ By design, the variable for being a "mover" is intended to capture a long-term absence from the country. According to the algorithm used by the Central Bureau of Statistics, a short visit back to Israel in the midst of a long-term absence does not change the status from "mover" to being a "non-mover."

There are a few potential weaknesses of the data worth noting. First, the data set does not indicate why a person leaves and whether the person intends to come back or not. The person may not know this information himself. Therefore, although we mainly use the given measure of a "mover" throughout our analysis, we check the robustness of our results by classifying only longer-term movers as "movers" (using the information about when the person moved). In addition, as we discuss below, there is strong evidence to believe that the measure we received is picking up moves which are indeed long term. A second weakness in the data is that it does not contain information on where the person is living if he/she resides outside of the state of Israel. However, the Global Migrant Origin Database Version 4.0 indicates that the United States is by far the most likely destination for Israeli emigrants. ${ }^{7}$ Therefore, we treat the United States as the "host" country of interest. To the extent that the United States is not the actual destination for a particular emigrant, this should only add noise to the analysis.

Descriptive statistics for the main variables of interest from the 1995 Israeli Census are presented in Table 1. It is important to keep in mind throughout the analysis that all variables are measured in 1995, except for the information about whether the person is considered a "mover" or not. Since the focus of the paper is to determine the selection of emigrants in terms of their education and wages, we restrict the analysis to males with a strong attachment to the labor force, who are old enough to finish their schooling (Israelis typically start their BA studies at 22-24 years old) but young enough so that they are not leaving for retirement purposes. Specifically, we restrict the sample to Jewish males between the ages of 30 and 45 who were not self-employed (so their income measure is reliable), worked at least 30 hours a week, worked at least six months in the previous year,

\footnotetext{
${ }^{6}$ The Israel Central Bureau of Statistics received information from the Interior Ministry about who is leaving the country, which the Interior Ministry collects at the airports and borders according to the personal identification number.

${ }^{7}$ The data in the Global Migrant Origin Database Version 4.0 is problematic since it is based on country of birth, and many Israelis were not born in Israel. Also, it does not distinguish between Jewish and Arab Israelis, while this study focuses on the emigration status of the Jewish population. However, according to the database, 122,591 Israelis moved to the US and the next highest country (excluding Arab countries) is Canada with a total of 17,393 . Therefore, the United States is by far the most likely destination country.
} 
and are not ultra-orthodox.

Table 1 shows that the overall rate of emigration as of 2004 in this sample stands at 1.6 percent. The rate as of 2002 was 1.3 percent, so there appears to be an increase over time. Over 67 percent of those characterized as "movers" in 2004 emigrated by the end of 2000. In addition, only two percent of those characterized as a "mover" in 2002 returned to Israel by the end of 2004. So, our measure of a "mover" appears to be picking up longer term stays abroad. Table 1 also contains means for the other variables used throughout the analysis: education (13.0 years of education), age (37.7), native (61.4 percent were born in Israel), marital status (90 percent married), number of children (2.13), and monthly wages.

Although the overall rate of emigration appears to be rather low at 1.6 percent, there are stark differences across levels of education and wages. Figure 1a presents the rates of emigration across different levels of education. The rate for those with a high school education or less is about 1.1 percent, but the rate increases significantly for college graduates to 1.6 percent, and then jumps dramatically for those with an MA degree or higher to 4.6 percent. The high emigration rate for the most educated Israelis has raised concerns within Israel about a significant "brain drain." Figures 1a and 1b show similar patterns for natives and non-natives, but the magnitudes are much higher for non-natives. ${ }^{8}$ It is worth noting that these patterns are not due to restricting our sample to those above the age of 30, which could lead to a similar pattern if less-educated Israelis tend to leave in their 20's while more educated individuals wait until they finish schooling. Figure 2a shows that the probability of emigrating increases with education even for those in their 20's. In addition, Figure 2b shows that emigration rates by 2004 for teenagers in 1995 increase with their father's education level. Therefore, all the evidence suggests that emigrants are indeed positively selected according to family background and education during their teenage years and into their mid-40's.

The positive relationship between education and the rate of emigration is very consistent with the predictions of the Borjas model. Specifically, the Borjas model predicts that the propensity to emigrate should increase with education in a country with a low return to education in comparison to a potential host country. Indeed, conventional OLS estimates of the returns to education in Israel are quite low. Table 2 presents Mincer-like wage regressions using data from the US and Israel from the same period and using similar

\footnotetext{
${ }^{8}$ Gould and Moav (2007) show that the rate of emigration is very high for professors, scientists, doctors, and engineers. All of these groups are at least three times higher than teachers or workers in all the rest of the occupations.
} 
sample selection criteria. The estimated return to education is 10.0 percent for the US and only 7.1 percent for Israel. This differential is likely to be a factor which is generating the positive relationship between education and emigration in Figures $1 \mathrm{a}$ and $1 \mathrm{~b}$. It is worth noting that this relationship is positive and significant after controlling for a host of other demographic characteristics of the individual, as shown in a regression in the third column of Table 2 .

However, one potential explanation for the pattern exhibited in the figures could be that individuals with higher education levels are more likely to spend time temporarily abroad (sabbaticals, being stationed abroad by a firm or the government, etc.). However, we find no evidence to support this idea. Figure 3 shows that there is no discernible relationship between education and the propensity to return between 2002 and 2004, given that you were considered a "mover" in 2002. The last column of Table 2 confirms that there is no systematic pattern between "returning" and education levels even after controlling for other demographic characteristics and wages. Therefore, we believe that the patterns in the data are unlikely to be picking up the tendency for highly educated individuals to work for a year or two abroad.

However, the increasing likelihood of higher educated individuals to emigrate could possibly be explained by other factors, and therefore, variation in the relative returns to education is needed to truly test the predictions of the Borjas model. To do this, we estimate the returns to education within sectors in the United States using the same specification used in the first column of Table 2, and within sectors in Israel using the specification in second column of Table 2. Table 3 presents the estimated returns to education in the US and Israel when the sectors are defined by industry, and Table 4 presents the estimates when the sector is defined by occupation. In our main empirical analysis, we will exploit variation in the relative returns to education (Israel versus the US) across sectors to test the predictions of Borjas model regarding the selection of Israeli emigrants from each sector.

Although most of the literature examining the Borjas model looks at whether there is a positive or negative selection of emigrants according to their education (observable skills), the model in Borjas (1987) also applies to unobservable skills. We measure the returns to unobservable skill with residual inequality (see Juhn, Murphy, and Pierce (1993)). The first two columns in Table 2 show that the residual variation is higher in the US versus Israel, after controlling for a similar set of demographic characteristics. Specifically, the "Root MSE" from the Mincer-like wage regression is 0.523 for the US and 0.498 for Israel. 
According to the Borjas model, the higher return to unobservable skill in the US should entice individuals with higher residual wages to emigrate. However, a simple descriptive analysis is not exactly consistent with this prediction. The third column in Table 2 shows that wages are not a significant predictor of who moves, and Figure 4 shows that the propensity to emigrate increases with residual wages and then declines. That is, it is not the case that no pattern exists at all between residual wages and the propensity to leave Israel. Rather, the pattern is non-linear - characterized by an inverse U-shape. Apparently, individuals with very low residual wages and very high residual wages are less likely to emigrate than those in the middle of the distribution, which is not consistent with a simple Borjas model. As shown in Figures 5 and 6, this pattern persists even if after controlling for twelve industry categories or eight occupation groups.

Chiquiar and Hanson (2005) also found that, in contrast to the predictions of the Borjas model, emigrants from Mexico come from the middle part of the education distribution rather than being concentrated in the lower tail (since the returns to education in Mexico are higher than they are in the US). The reconciled their findings by adapting the Borjas model by including a cost of emigration which declines with education. Therefore, they explain the lower rate of emigration by low educated workers in Mexico by their high costs of moving, and the lower rate of emigration of highly educated workers by the higher return to education in Mexico. Our case is obviously different, since our evidence regarding the nature of the selection on education (observable skills) is entirely consistent with the Borjas model without any adaptations. In addition, the adapted model by Chiquiar and Hanson (2005) cannot explain the inverse U-shape in our data regarding unobservable skills - since their case involved a scenario where the return to skill was higher in the country of origin (Mexico), and our case involves a lower return in Israel versus the US. A higher cost of moving for workers with low income could explain why workers with very low residual wages do not emigrate in large numbers, but a higher return to unobservable skill in the US should entice the upper tail of the residual wage distribution in Israel to emigrate at a high rate. The fact that it declines for workers in the upper tail may be due to the idea that some factors of their success are unlikely to be transported to the US.

In the next section, we formally show that incorporating the idea that some skills are "country-specific" into the model can generate the inverse U-shaped relationship between residual wages and the likelihood of emigrating. In this sense, the U-shaped pattern is consistent with our model, but it may also be the result of unobserved factors. Again, variation in the returns to unobservable skill is needed to test the implications of our model, 
and for this purpose, we estimate the returns to unobserved skill in each sector using the same set of regressions within each sector described above regarding the estimation of the rates of return to education in each sector. The "root mean squared error" from each regression is the estimated return to unobserved skill in each sector in the US and Israel, and Tables 3 and 4 present these estimates for the different industries and occupations. In our main empirical analysis, we will exploit variation in the relative returns to unobservable skills (Israel versus the US) across sectors to test the predictions of our model regarding the nature of the selection of emigrants with regard to unobservable skills.

\section{A Model of Emigration with Country-Specific Skills}

In this section, we present a model of the emigration decision which takes into consideration the idea that some skills are country-specific. A significant portion of an individual's total human capital is likely to be country-specific for several reasons. First, any skill which is "firm-specific" is likely to be country-specific as well. Second, language and cultural barriers may prevent an individual from transferring their skills to a country where they lack a commanding knowledge of the local language, cultural of business practices, consumer tastes, laws, and regulations. Third, if a person's success is at least partially due to luck (being in the right place at the right time), good luck may not be transferable abroad. Fourth, many individuals with high incomes became successful due to personal connections with local individuals and authorities, and these connections will not be useful in a foreign country. For these and other reasons, it is very likely that some people will not be able to translate their success to a foreign country.

The model consists of individuals living in the source country (country 0) and deciding whether or not to emigrate to the host country (country 1). An individual's wage in the source country, $w_{0}$, is determined by his level of education, $e$, and by his unobservable (to the econometrician) skills. Unobservable skills are composed of skills which are country-specific, $s$, and skills which are more general, $g$. Education is considered a general skill which is also observable. An individual's wage, $w_{0}$, in the source country is modeled by:

$$
w_{0}=a_{0}+e+g+s,
$$

where $a_{0}$ is the intercept of the wage function and is constant across individuals. Without any loss of generality, the returns to each type of skill $(e, g$, and $s)$ are normalized to one 
in country 0 . The two unobservable components, $s$ and $g$, are distributed independently with a uniform distribution over the unit interval,

$$
\begin{aligned}
& s^{\sim} U[0,1] ; \\
& g^{\sim} U[0,1] .
\end{aligned}
$$

Using the uniform distribution simplifies the analysis, but has no effect on the qualitative results.

If an individual chooses to emigrate to the host country (country 1 ), he will receive the following wage (net of the direct cost of moving to another country),

$$
w_{1}=a_{1}+\beta_{1} e+\gamma_{1} g-f
$$

where $a_{1}$ is the intercept of the wage function in country $1, \beta_{1}$ and $\gamma_{1}$ are the returns to $e$ and $g$ in country 1 , and $f$ is the direct cost of relocating which is considered identical across all individuals. Although several papers model the cost of moving as a decreasing function of education (Chiswick (1999) and Chiquiar and Hanson (2005)), adding this element to the model will only strengthen the results for positive selection on education, but would not enable us to understand the inverse $\mathrm{u}$-shaped pattern of emigration rates according to residual wages, as depicted in the preceding section. ${ }^{9}$ The key assumption of the model is that some skills are not directly transferable to the host country, and therefore, are lost due to emigration. This is captured by setting the return to unobserved country-specific skills, $s$, to zero in country 1 . In contrast, despite the fact that $g$ is also unobservable to the researcher, it is rewarded in the host country since it is considered a general skill.

We restrict our analysis to the case where the returns to education and general skills are higher in the host country versus the source country, since Section II shows that this appears to be the case for Israelis who are considering a move to the United States. Formally, this assumption is represented by $\beta_{1} \geq 1$ and $\gamma_{1} \geq 1$.

Following the framework developed by Roy (1951) and Borjas (1987), the decision to emigrate is based on wage maximization. Therefore, individuals emigrate if and only

\footnotetext{
${ }^{9}$ The other papers use the declining costs of emigration to explain why emigrants are not negatively selected when the return to education in the source country (Mexico) is higher than the return in the host country (United States). Since the returns to education are lower in Israel versus the United States, adding this element to the model only reinforces the positive selection of Israeli emigrants in terms of education. Formally, making the direct cost relocating, $f$, a function of education or general skills, is equivalent to a change in the difference in the relative returns to education or general skills between the two countries. This has no qualitative impact on the model, unless the cost is increasing with skill and/or education in a rate that can reverse the direction of the difference. However, given the literature which argues that the costs decline with skill, this possibility is not very reasonable.
} 
if $w_{1}>w_{0}$. Based on equations (1) and (2), this condition holds if and only if:

$$
\beta e+\gamma g>a+s
$$

where $a=\left(a_{0}-a_{1}\right)+f$ is the total fixed-cost of emigration (the difference in the constant plus the direct cost of relocating), $\beta=\beta_{1}-1 \geq 0$, and $\gamma=\gamma_{1}-1 \geq 0$. The parameters $\beta$ and $\gamma$ are the differences in the returns between country 1 and country 0 to education and general skills respectively. Hence, the right hand side of equation (3), $a+s$, is the total emigration cost including the loss of specific skills, whereas the left hand side, $\beta e+\gamma g$, is the gain from emigration. Naturally, an individual decides to emigrate if the gain is greater than the costs.

As stated above, an individual's unobservable component of income in country 0 is represented by $s+g$. This sum is called the individual's "residual wage," and is denoted by $\tilde{w}$, i.e.,

$$
\tilde{w}=s+g .
$$

Since both $s$ and $g$ are distributed uniformly over the unit interval, it follows that the residual wage, $\tilde{w}$, is distributed between 0 and 2 . In order to focus the model on the most realistic range of results, a few restrictions on the parameters are useful. In particular, we restrict the parameters so that not everyone emigrates. Since the returns to education, $e$, and general skills, $g$, are higher in country 1, individuals with a high level of $e$ and $g$ are the most likely to gain from emigration. Equation (3) formally illustrates this point, as the benefits of emigration increase with both $e$ and $g$. In contrast, individuals with the lowest levels of $e$ and $g$ are the least likely to gain from emigration. Therefore, in order to ensure that not everyone emigrates, we assume that for any individual characterized by the minimum levels of education and general skills $(g=e=0)$, the return to emigration is negative, $w_{1}<w_{0}$. (If this holds, then it holds for any level of $s$ as well.) Formally, we assume that:

$$
a>0,
$$

so that condition (3) does not hold for any individual characterized by $g=e=0$, regardless of $s$. Assumption A1 implies that a positive total fixed-cost of emigrating, represented by $a$, causes those with the least to gain from emigration to choose not to emigrate.

Next, we focus on a different set of individuals who are very unlikely to emigrate those with low education and high country-specific skills. The condition in equation (3) 
shows that the net benefits of emigration increase with $e$ and decline with $s$ - the latter result stemming from the high loss of country-specific skills should the individual choose to move. The only reason individuals with low $e$ and high $s$ would ever choose to emigrate is because the return to $g$ is extremely high in country 1 . Therefore, to preclude this unreasonable case, we restrict the return to $g$ in country 1 to be no more than double the return to $g$ in country 0. Formally, we assume that:

$$
\gamma<1
$$

which assures that equation (3) does not hold for any individual with $e=0$ and $s=1$, regardless of $g$.

Although low educated individuals are the ones most likely to stay, we do not restrict all of them to do so. In fact, we restrict the parameters so that not everyone with the lowest education chooses to stay. In particular, for an individual with the lowest education ( $e=0$ ), equation (3) holds if $g \gamma>a+s$, which is most likely to be satisfied if $g$ is high and $s$ is low. Therefore, we assume that the return to $g$ is sufficiently high so that:

$$
\gamma>a
$$

assuring that condition (3) holds for an individual with $g=1$ and $s=0$, regardless of $e$ (as long as $\beta \geq 0$ ).

We now derive the probability of emigration for any individual with a given level of education $e$ and a given residual wage, $\tilde{w}$. We condition on these two variables since these are observable to the econometrician, while the individual components of the residual wage, $g$ and $s$, are not observable. Since the distributions of $g$ and $s$ are uniform and independent, it follows that for any given $\tilde{w}, g$ is uniformly distributed in its feasible range. ${ }^{10}$ In particular, the conditional distribution of $g$ given $\tilde{w}$ is given by:

$$
\begin{aligned}
& g^{\sim} U[0, \tilde{w}] \quad \text { for } \quad \tilde{w} \leq 1 \text {; } \\
& g^{\sim} U[\tilde{w}-1,1] \text { for } \tilde{w} \geq 1 \text {, }
\end{aligned}
$$

These properties allow for a straightforward calculation of the probability that an individual with any given $\tilde{w}$ and $e$ will emigrate, which we denote by $p(\tilde{w} ; e)$. As follows from equation (3), and noting that $s=\tilde{w}-g, p(\tilde{w} ; e)$ is given by:

$$
\begin{aligned}
p(\tilde{w}, e) & \equiv p(\gamma g+\beta e>a+s \mid \tilde{w}) \\
& =p\left(g>\frac{a-\beta e+\tilde{w}}{1+\gamma} \mid \tilde{w}\right) .
\end{aligned}
$$

\footnotetext{
${ }^{10}$ Note that the probability that $s+g \in(w-\varepsilon, w+\varepsilon)$, for $\varepsilon \rightarrow 0$, for any given $g$, such that $\tilde{w}-g<1$ is independent of $g$,and therefore the conditional probability of $s$ and $g$ for any given $\tilde{w}$ are uniform in the feasible range.
} 
We further suppose that $a$ is sufficiently large relative to $\beta$, so that the distribution of $e$ is bounded from above by $a / \beta$. This implies that the return to education in country 1 versus country 0 is not so large that a majority of highly educated people decide to emigrate. (This coincides with the case of Israel - the highest emigration rates are for those with MA degrees, but the rate is still only $4.6 \%$ over the seven-year period we study.) This assumption implies that the residual wage, and not just the level of education, plays an influential role in the decision to emigrate. Our assumption that $e$ is bounded from above by $a / \beta$, implies that $a-\beta e>0 .{ }^{11}$ All proofs are in the appendix.

Proposition 1 (The properties of $p(\tilde{w}, e))$. Under Assumptions A1-A3 and as long as $a-\beta e>0$,

1. The probability that an individual decides to emigrate is:

$$
p(\tilde{w}, e)=\left\{\begin{array}{ccc}
0 & \text { for } & \tilde{w} \leq \frac{a-\beta e}{\gamma} \\
\frac{\gamma}{\gamma+1}-\frac{a-\beta e}{(1+\gamma) \tilde{w}} & \text { for } & \tilde{w} \in\left(\frac{a-\beta e}{\gamma}, 1\right) \\
\frac{1+\gamma-(a-\beta e-\tilde{w}}{(2-\tilde{w})(1+\gamma)} & \text { for } & \tilde{w} \in[1,1+\gamma-(a-\beta e)) \\
0 & \text { for } & \tilde{w} \geq 1+\gamma-(a-\beta e)
\end{array}\right.
$$

where,

2. $p(\tilde{w}, e)$ is continuous

3. $\frac{a-\beta e}{\gamma} \in(0,1)$

4. $1+\gamma-(a-\beta e) \in(1,2)$

5. $p(1, e) \in(0,1 / 2)$

6. $p(\tilde{w}, e)$ is increasing and concave with respect to $\tilde{w}$ for $\tilde{w} \in\left(\frac{a-\beta e}{\gamma}, 1\right)$

7. $p(\tilde{w}, e)$ is decreasing and concave with respect to $\tilde{w}$ for $\tilde{w} \in(1,1+\gamma-(a-\beta e))$.

According to Proposition 1, the probability to emigrate is an inverse u-shaped function of the residual wage, $\tilde{w}$, if $\beta$ and $\gamma$ are not too high and $a$ is sufficiently high. The intuition is rather straightforward. Generally speaking, individuals with a low residual income have low levels of both general and country-specific skills ( $g$ and $s$ ). A low $g$ implies that the individual has a limited incentive to emigrate in order to enjoy the higher return to $g$ in country 1 , while a low $s$ means that he will suffer a small loss in terms of losing his country-specific capital if he moves. These effects offset each other, so that the net gain to emigration for this individual is modest, and therefore, he will tend not to emigrate due to the significant fixed-costs of emigration, $a$. On the other end of the spectrum, individuals

\footnotetext{
${ }^{11}$ We briefly discuss below the case where $a-\beta e<0$.
} 
with very high residual wages will tend to have high levels of general and country-specific skills. For these individuals, a high level of $g$ implies a larger benefit to emigrating, while a large $s$ means that he will suffer a severe loss of country-specific skills. That is, similar to the individual with a low residual wage, the ratio of $g$ to $s$ is close to one, and therefore, the costs and benefits of emigration roughly cancel each other out. As a result, a significant level of fixed emigration costs will prevent individuals with a high residual wage from leaving the country in large numbers.

Now, consider those in the middle of the residual wage distribution. In this range, individuals have varying levels of $s$ and $g$. Those with high levels of $s$ versus $g$ will behave similar to those at the tails of the distribution since the loss of country-specific skills and the fixed-costs will prevent them from leaving at a large rate. However, in the middle of the distribution, there is a significant group of people with high levels of $g$ relative to $s$, and for those individuals, the return to emigration is high enough to produce the largest rate of emigration within the population. As a result, the rate of emigration tends to be larger in the middle of the residual wage distribution than in the tails. ${ }^{12}$

It is important to note how our results differ from the existing framework developed by Borjas (1987). In his model, the selection of immigrants in terms of "unobservable skill" is significantly influenced by the correlation of unobservable skills in the source and host countries. Our model is different since the correlation between an individual's unobservable skill in both countries is different across people, rather than being a single parameter. In particular, due to the variation in the level of country-specific skills across people, some individuals stand to lose a large portion of their total unobservable skill and some would lose virtually nothing. That is, our model produces a different rate of transferability of unobservable skill across people according to the relative size of each component of unobservable skill. By showing that a larger proportion of individuals with a higher transferability rate of unobservable skills (i.e. those with a high $g$ relative to $s$ ) exists in the middle of the distribution of total unobservable skill (i.e. the residual wage), our model is able to explain the inverse $\mathrm{u}$-shaped pattern of emigration in relation

\footnotetext{
${ }^{12}$ It should be noted that the inverse u-shaped relationship between the residual wage and the probability of emigration does not depend on our assumption that the two components of the residual, $s$ and $g$, are uncorrelated. The u-shape patterns persists for any type of correlation except for the case where they are perfectly, positively correlated (which would produce positive selection). However, the u-shaped pattern becomes flatter when the correlations becomes more positive. Interestingly, a negative correlation will strengthen the inverse u-shape pattern, since a more negative correlation would increase the variance in the distribution of $s$ and $g$ in the middle of the distribution of their sum, and hence a higher probability of $g$ exceeding its threshold level for triggering emigration. Also, it is worth noting that the results do depend on the relative variances of $s$ and $g$.
} 
to unobservable skill.

We now examine the effect of education on the shape of the probability function of emigrating, $p(\tilde{w}, e)$.

Proposition 2 (The effect of e on $p(\tilde{w}, e))$.Under Assumptions A1-A3 and as long as $a-\beta e>0$,

1.

$$
\frac{d p(\tilde{w}, e)}{d e}>0 \quad \text { for } \quad p(\tilde{w}, e)>0
$$

2.

$$
\frac{d^{2} p(\tilde{w}, e)}{d e d \tilde{w}}<0 \quad \text { for } \quad \tilde{w} \in\left(\frac{a-\beta e}{\gamma}, 1\right)
$$

3.

$$
\frac{d^{2} p(\tilde{w}, e)}{d e d \tilde{w}}>0 \quad \text { for } \quad \tilde{w} \in(1,1+\gamma-(a-\beta e))
$$

Part 1 of Proposition 2 implies that the probability of emigrating increases with the level of education. In other words, emigrants are positively selected in terms of their education, which follows from the higher return to education in country 1 versus country $0, \beta>0$. This result and its mechanism is similar to the prediction in Borjas (1987). However, Proposition 2 demonstrates that the marginal effect of $e$ on $p$ is decreasing with $\tilde{w}$ for $\tilde{w}<1$ (part 2), and increasing with $\tilde{w}$ for $\tilde{w}>1$ (part 3). That is, the inverse u-shaped pattern of $p(\tilde{w}, e)$, with respect to $\tilde{w}$ is shifting up and flattening out as $e$ increases.

For the case where $a-\beta e<0$, the results are generally in the opposite direction: $p(\tilde{w}, e)=1$ for both high and low levels of $\tilde{w}$, and the lowest value of $p(\tilde{w}, e)$ is in the middle of the distribution of $\tilde{w}(\tilde{w}=1)$. Since this pattern is not observed in the data, we focus our analysis on the case where $a-\beta e>0$.

We now examine how the pattern of emigration across different levels of $\tilde{w}$ changes as the return to $g$ increases in country 1 .

Proposition 3 ("mean preserving spread") A rise in the return to unobservable general skills in the host country versus the source country, $\gamma$, and in the fixed cost of emigrating, $a$, such that $p(1, e)$ is held constant, generates a decline in $p(\tilde{w}, e)$ for $\tilde{w}<1$, and a rise in $p(\tilde{w}, e)$ for $\tilde{w}>1$. 
It follows from Proposition 3 that a rise in $\gamma$, while holding $p(1 ; e)$ constant, generates a shift to the right in $p(\tilde{w} ; e)$ around the point $p(1 ; e)$. In other words, a higher relative return to unobservable general skills in country 1 , while holding $p(1 ; e)$ constant, maintains the overall u-shaped pattern of emigration according to residual wages, but shifts the whole curve to the right (raising emigration rates for those with high residuals and lowering the rate for low residual wages).

The intuition for this result is as follows. For a given $e$, the decision to emigrate depends on both $g$ and $s$. The benefits of emigration increase with $g$, while the costs increase with $s$. Therefore, as $\tilde{w}$ increases, the sum of $s$ and $g$ increases, which implies that the threshold level of $g$, above which individuals choose to emigrate, increases with $\tilde{w}$. To derive this formally, the condition for a person with any given $\tilde{w}$ to decide to emigrate, given by equation (3), can be re-written as,

$$
\beta e+\gamma g>a+\tilde{w}-g
$$

where $\tilde{w}-g=s$. Re-arranging implies: $\beta e+(1+\gamma) g>a+\tilde{w}$, and therefore, for any $\tilde{w}$ and $e$, there exists a threshold level of $g$, denoted by $\hat{g}(\tilde{w}, e)$, such that equation (3) holds with equality:

$$
\hat{g}(\tilde{w}, e)=\frac{a-\beta e+\tilde{w}}{1+\gamma} .
$$

Hence, the threshold level of $g$ is increasing with $\tilde{w}$, and therefore a rise in the difference in the return to general skills, $\gamma$, has a stronger impact on individuals with larger residual wages, $\tilde{w}$. This can also be seen from equation (3), where the marginal benefit of emigrating with respect to $\gamma$ is equal to $g$. Therefore, those with higher $g$ are more sensitive to changes in $\gamma$. This general result is independent of the specific "mean preserving spread" exercise performed in the proposition. ${ }^{13}$

We now examine how the positive selection of emigrants, as shown in Proposition 2 , is affected by changes in the relative returns to education between the two countries. To do this, we derive the probability of emigrating as a function only of education, and discuss its properties.

Proposition 4 (the effect of education on the emigration probability) Under A1-A3, for $\beta>0$ :

\footnotetext{
${ }^{13} \mathrm{~A}$ rise in the fixed cost, $a$, has a negative effect on the emigration probability. However, this effect declines (in absolute value) with $\tilde{w}$ for $\tilde{w}<1$, in particular, for $\tilde{w} \in\left(\frac{a-\beta e}{\gamma}, 1\right), \frac{d^{2} p(\tilde{w}, e)}{d a d \tilde{w}}=\frac{1}{\tilde{w}^{2}(\gamma+1)}>0$.For $\tilde{w}>1$ the opposite is true. For $\tilde{w} \in(1,1+\gamma-(a-\beta e)), \frac{d^{2} p(\tilde{w}, e)}{d a d \tilde{w}}=-\frac{1}{(\gamma+1)(w-2)^{2}}<0$.
} 
1. The probability of emigrating as a function of education is:

$$
p(e)=\frac{(\gamma-a+\beta e)^{2}}{2 \gamma}>0 .
$$

2. The probability of emigrating is an increasing and convex function of education:

$$
\begin{gathered}
\frac{\partial p(e)}{\partial e}=\frac{\beta}{\gamma}(\gamma-a+\beta e)>0, \\
\frac{\partial^{2} p(e)}{\partial e^{2}}=\frac{\beta^{2}}{\gamma}>0 .
\end{gathered}
$$

3. The probability of emigrating as a function of education increases and becomes steeper with an increase in the return to education in country 1 relative to country 0 :

$$
\begin{gathered}
\frac{\partial p(e)}{\partial \beta}=\left(1-\frac{a}{\gamma}+\frac{\beta e}{\gamma}\right) e>0, \\
\frac{\partial^{2} p(e)}{\partial e \partial \beta}=1-\frac{a}{\gamma}+\frac{2 \beta e}{\gamma}>0 .
\end{gathered}
$$

Proposition 4 states once again that emigrants are positively selected in terms of education (part 1), and that the shape of the relationship between education and the probability of emigrating is convex (part 2). Part 3 of the proposition indicates that an increase in the return to education in the host country makes the curve shift up and become steeper. In other words, an increase in the return to education in country 1 increases the overall level of emigration from country 0 , and intensifies the positive selection of those that choose to emigrate in terms of education levels.

Although $g$ is not observable to the econometrician, we now describe the patterns of emigration in relation to different levels of this general skill. As follows from the emigration condition (3), for any level of $g$ and $e$, there is a threshold level of specific skills $s$, below which the individual decides to emigrate:

$$
\hat{s}=\gamma g-(a-\beta e) .
$$

Noting that under the restriction that $a-\beta e>0$ there is a threshold level of $g=(a-\beta e) / \gamma$ below which there is no emigration, the probability to emigrate as a function of $g$ is given by:

$$
p(g)=\left\{\begin{array}{cc}
0 & g<(a-\beta e) / \gamma \\
\gamma g-(a-\beta e) & g \in[(a-\beta e) / \gamma, 1]
\end{array}\right.
$$


where it follows from our restrictions $(g \leq 1$ and $\gamma<1)$ that the probability of emigration is strictly smaller than 1 for any $g$ as long as $a-\beta e>0$. Hence, above the threshold level, the emigration rate is a linear increasing function with a slope equal to $\gamma$. Similar to the results regarding the observable general skill, $e$, a higher return to $g$ in country 1 versus country 0 generally produces positive selection in terms of $g$.

Overall, the theory presented in this section shows that a higher return to observable and unobservable general skills in the host country versus the source country, combined with the presence of country-specific skills in the source country, can generate the patterns in the data seen in Section II. In particular, the model shows that emigrants are positively selected in terms of their education, and that the relationship is convex (as shown in Figures 1a and 1b). However, the relationship between emigration rates and residual wages exhibits an inverse u-shaped pattern (as shown in Figures 4, 5, and 6). Increases in the returns to either type of skill in country 1 increase the positive selection of emigrants in terms of either skill, but keep the overall shape of the curve intact. These results demonstrate the general idea that there may be a non-monotonic relationship found in many countries between emigration and skill based on many other factors, but the basic premise of the Borjas model may still be relevant - an increase in inequality abroad shifts the curve in a way that intensifies the level of positive selection. In the next section, we examine the empirical relevance of the model's predictions.

\section{Selection on Observables (Education)}

The goal of this section is to test whether a lower relative return to education in Israel versus the US intensifies the positive relationship between education and the propensity to leave Israel (Propositions 2 and 4). With information on each individual in Israel before he makes the decision to leave the country or not, the basic regression specification explains the probability that person $i$ who works in sector $j$ (before leaving Israel) decides to emigrate from Israel by the following equation:

$$
\begin{aligned}
\operatorname{Pr}\left(\text { Mover }_{i j}\right)= & \gamma_{0}+\gamma_{1} x_{i}+\gamma_{2} \text { educ }_{i}+\gamma_{3}(\text { residual wage })_{i j}+\gamma_{4}(\text { residual wage })_{i j}^{2} \\
& +\gamma_{5}(\text { Israel ROR Educ })_{j}+\gamma_{6}(\text { US ROR Educ })_{j} \\
& +\beta_{1}(\text { Israel ROR Educ })_{j} \cdot \text { educ }_{i}+\beta_{2}(\text { US ROR Educ })_{j} \cdot \text { educ }_{i} \\
& +\alpha_{j}+\varepsilon_{i}
\end{aligned}
$$


where:

Mover $_{i j}$ is an indicator equal to one if the person emigrates from Israel and is zero otherwise;

$x_{i}$ is a vector of personal characteristics (age, marital status, number of children in the household, an indicator for being a native Israeli or not, age that the person moved to Israel (if he is not a native)), and dummy variables for ethnicity (European descent or Middle Eastern descent);

$e d u c_{i}$ is the number of completed years of schooling by person $i$;

residual wage $_{i j}$ is the individual's residual from a standard Mincer-like wage regression from the 1995 Israel Census using observations of workers in sector $j$ (regressing wages on education, age, age squared, marital status, and indicators for ethnic status and immigrant status);

Israel ROR Educ $c_{j}$ is the estimated return to education from the 1995 Israel Census in sector $j$ in the regression described above for estimating the residual wage for each person in sector $j$;

US ROR Educ $c_{j}$ is the estimated return to education from the US CPS (combining 1994, 1995, and 1996) within workers in sector $j$ using the specification in the first column of Table 2;

$\alpha_{j}$ is a fixed-effect for sector $j$; and $\varepsilon_{i}$ is the error term.

The coefficient $\gamma_{2}$ will determine whether there is a general relationship between schooling and the probability to leave Israel, while $\gamma_{3}$ and $\gamma_{4}$ will indicate whether higher residual wages within a given individual's sector increase or decrease the probability of emigrating (and whether the relationship is linear or non-linear). The analysis uses "residual wages" as a proxy for the return to unobservable skill, so that we can explicitly separate the effect of observable skill (education) from unobservable skill on the probability of leaving Israel. For both Israel and the US, we use estimates for the return to education in sector $j$ as a proxy for the return to observable skill (education) in sector $j$ in each country (using the specifications in the wage regressions in Table 2).

In the context of the model, the main coefficients of interest are $\beta_{1}$ and $\beta_{2}$. The model has no clear predictions on whether a higher relative return to observable skill will increase or decrease the overall rate of emigration from the source country. In fact, with the inclusion of fixed-effects for each sector, the parameters on these variables $\left(\gamma_{5}\right.$ and $\left.\gamma_{6}\right)$ are not even identified. The model does predict, however, that a lower (higher) relative return to skill in Israel versus the US will entice higher (lower) skilled workers to leave 
Israel. Formally, this prediction is represented by $\beta_{1}<0$ and $\beta_{2}>0$. These parameters are identified by exploiting variation across sectors in the difference between Israel and the US in the returns to education within each sector, and testing for whether the probability of emigration increases (decreases) with education in sectors with a lower (higher) return to education in Israel versus the United States.

It is important to emphasize that we are not assuming that all emigrants move to the US, although as indicated previously, the US is by far the most likely destination for Israeli emigrants. Nor do we assume that Israeli emigrants do not change sectors (there are too few observations in the 2000 U.S. Census to conduct a serious analysis of the Israeli emigrants in our sample living in the US). Rather, we allow the regression to answer the question of whether these factors are empirically relevant. If Israelis do not consider the relative returns to skill between the US and Israel within their own sector (and how it interacts with their own skill level), then the causal effect of these variables should be zero $\left(\beta_{1}=0\right.$ and $\left.\beta_{2}=0\right)$, and the estimates should be insignificant.

The inclusion of sector-specific fixed-effects controls for any unobserved heterogeneity in tastes for emigration across sectors. Therefore, the main identifying assumption throughout the paper is that the difference between the US and Israel in the estimated return to skill (either the return to education or the residual variation) within a sector is not systematically correlated with an unobserved taste for emigration by higher skilled individuals relative to lower skilled individuals.

In terms of defining the sectors, we use either the twelve industrial sectors depicted in Table 3 or the nine occupations in Table 4 . Sectors have to be defined rather broadly so that we can obtain reasonable estimates of the returns to education and residual variation (used in the next section) within each sector. Also, we need a reasonable number of emigrants within each sector in order to test for selection. Tables 3 and 4 present the returns to education within each sector in Israel and the US. Differences in these estimates across sectors are the source of the "treatment variation" that is exploited in the empirical analysis. ${ }^{14}$

Table 5 presents the main analysis for selection on observable skill when sectors are defined by the twelve industries displayed in Table 3. The coefficients presented in all of

\footnotetext{
${ }^{14}$ Although there is a large literature which examines the bias in the estimated returns to schooling using a standard Mincer-like regression, this issue should only affect our results if the biases across sectors and between the US and Israel are somehow systematically related to the selection of workers within a sector. If the estimated returns to schooling are biased, this should only add noise to the regression. It is difficult to imagine why differential biases between the US and Israel across sectors would somehow be correlated with the relationship between skill and the propensity to emigrate.
} 
the regression tables represent the estimated marginal effect of each explanatory variable (evaluated at the means of all the explanatory variables). The first column of Table 5 shows the estimates of the regression equation using fixed-effects for each industry, but using only the returns to education in Israel (excluding the return to education in the United States). The results show that education is positively and significantly related to the probability of emigrating (Proposition 2), and the coefficients on the residual wage and its quadratic term $\left(\gamma_{3}\right.$ and $\left.\gamma_{4}\right)$ indicate that the relationship between emigration and residual wages is concave, which is consistent with Proposition 1. However, we postpone our discussion of selection on unobservables until the next section which is dedicated to this issue alone.

The main parameter of interest in the first column of Table 5 is not significant - the interaction of education with the return to education in Israel. In the second column, we include only the return to education in the US, thus omitting the return to education in Israel. In this specification, the interaction between education and the return to education in the US is positive and significant, and indicates that higher educated Israelis tend to leave Israel more if they work in a sector which has a high return to education in the United States. The direction of this effect is consistent with the predictions of the model - positive selection is larger in a sector with a higher return to general skills abroad.

The third column of Table 5 includes the returns to education in the US and Israel. Interestingly, both of the main parameters of interest are now significant, and the magnitudes are much larger than in the first two columns. For example, the interaction between education and the return to education in Israel increases in size from -0.015 to -0.093 , while the interaction of education with the return to education in the US increases from 0.020 to 0.051 . The fact that the coefficients of interest are much bigger and significant when we include the interaction terms for the US and Israel together in the same regression is an important result in the context of the model. When we exclude the returns to skill in the US in column (1), the non-significant results for the interaction of education with the Israeli return to education indicate that high skilled workers are not generally more likely to leave Israel if they work in an industry with a low return to education. This is probably due to the positive correlation between the two countries in the returns to education. Therefore, a sector that has a high return to skill in Israel most likely has a high return as well in the US, and since the effect of the former is negative and the latter is positive, the coefficients are biased towards zero when we exclude the returns to skills in either country. This pattern of results highlights the importance of using variation in the relative returns 
to skill between the source and potential host country, and not just relying on the returns to skill in the source country in order to identify the parameters of the model.

Our finding that the relative returns between Israel and the US, and not the absolute returns in Israel, are what matters is strong evidence in favor of the implications of the model. In addition, the fact that the results are highly sensitive to the inclusion of the US measures of the returns to skill indicate that our measured returns to skill in the US and Israel are not simply measures of noise which are fraught with biases and measurement error. If this were the case, they should not be significant determinants of the probability to emigrate, and they should not be influencing the other coefficients to such a high degree.

The last column of Table 5 uses a specification which interacts a person's education level with the difference in the returns to education between Israel and the US in his sector. Using this specification, the main parameter of interest is highly significant: the probability of emigrating for Israelis with higher levels of education declines in sectors with a higher relative return to education in Israel versus the US. This result is consistent with the predictions of our model.

It is worth noting that these results are highly unlikely to be due to US immigration policy. Although US immigration authorities do consider the skill level and sector of work for each Israeli applying for a visa, the regressions control for sector-specific effects, and it is highly unlikely that US immigration authorities are running regressions within each sector in the US and Israel, and tailoring their policies to the relative returns within each sector between the US and a small country like Israel.

Table 6 presents the main results for selection on education after defining sectors according to occupations. It is important to note that the "wage residual" for each individual is not the same one used in the analysis using industries as sectors. The "wage residual" is now taken from regressions within the individual's occupation, rather than each individual's industry. Also, the returns to education in the US and Israel are now computed for occupations rather than industries.

Overall, the results using occupations as sectors are similar to those using industries in one respect, but differ in a few important ways. They are similar in the sense that higher educated Israelis tend to leave occupations with a low return to education in Israel. However, higher educated Israelis also tend not to leave Israel if the return to education in their occupation in the US is higher. The former result is consistent with the model but the later one is not. In the last column of Table 6 , the interaction of education with the difference in the returns to education between Israel and the US yields an insignificant 
coefficient, since the individual coefficients (in the first three columns) are of a similar magnitude and have the same sign. That is, the last column masks the two individual effects. However, even though one of the coefficients has an unexpected sign, it is worth noting that the size of the coefficients in the occupation level analysis are considerably smaller than the ones obtained in the industry-level analysis - less than half the magnitude of the coefficients in Table 5. Also, the difference in the results could be due to the idea that occupational status is already somewhat of a proxy for education, so testing for selection within occupations is really a test of selection within very small ranges of education. In contrast, the larger selection effects obtained in the industry-level analysis are most likely a product of exploiting a broader range of education levels within each industry.

We now examine the sensitivity of the results to different sample selection criteria and to different ways of defining a "mover." For the sake of parsimony, we present only the coefficient on the interaction between a person's education level with the difference in the return to education between Israel and the US in his sector (industry or occupation). We present results for both the industry and occupation level analysis, but restrict our discussion to the industry analysis since using occupations as sectors yields a consistently non-significant coefficient.

Table 7 presents the results for three different sample selection criteria. The first column replicates the last column of Tables 5 and 6 , while the next two columns compare the results obtained for natives versus non-natives (those not born in Israel). Figures 1a and $1 \mathrm{~b}$ show that non-natives have a higher rate of emigration, and that the positive relationship between education and the probability of emigrating is steeper as well. However, Table 7 shows that the results are more significant for natives rather than non-natives, although the sign of the coefficients for both groups are consistent with the model in the industry analysis. One possible explanation for the non-significant results for non-natives could be that many of those who choose to leave Israel are moving back to Russia, and therefore, measures of the returns to skill in the US may be less relevant for them. In the last column of Table 7, we delete industries with a small sample size from the regression (less than 1,000 observations), and the results are very similar to the results obtained from the entire sample. Therefore, the results are not coming from small sectors with influential outliers.

Table 8 presents results for different ways of defining a "mover." The first two columns compare the results obtained using "mover" status as of 2004 (the measure we have been using up to now) to "mover" status as of 2002. The results are a little weaker and less significant, but are generally similar using both definitions. The third column defines a 
"mover" as someone who is defined as a "mover" in both 2002 and 2004, and the results are still very similar. The last column defines a mover as someone who is categorized as a "mover" in 2004, but also has been out of the country since the end of 2000. Again, the results are significant but smaller in magnitude. Overall, the results appear to be robust to confining the status of "mover' only to those who have been out of the country for several years. We will discuss the magnitude of the results later, but first we present a similar analysis for the selection of emigrants on unobservable skill.

\section{Selection on Unobservables (Residual Wages)}

The section analyzes the prediction of Proposition 1 that the rate of emigration should be an increasing and then decreasing function of the residual wage, and Proposition 3's prediction that a higher relative return to unobservable skill in Israel versus the US increases the probability that individuals with higher unobserved skill will emigrate (i.e. shift the inverse U-shaped relationship between emigration and residual wages to the right). The basic regression specification explains the probability that person $i$ who works in sector $j$ (before leaving Israel) decides to emigrate from Israel by the following equation:

$$
\begin{aligned}
\operatorname{Pr}\left(\text { Mover }_{i j k}\right)= & \gamma_{0}+\gamma_{1} x_{i}+\gamma_{2} \text { educ }_{i}+\gamma_{3}(\text { residual wage })_{i j}+\gamma_{4}(\text { residual wage })_{i j}^{2} \\
& +\beta_{3}(\text { Israel residual } S D)_{j k} \cdot(\text { residual wage })_{i j} \\
& +\beta_{4}(\text { US residual } S D)_{j k} \cdot(\text { residual wage })_{i j} \\
& +\alpha_{j k}+\varepsilon_{i}
\end{aligned}
$$

where each variable is defined as before except:

Israel residual $S D_{j k}$ is the standard deviation of the residuals within sector $j$ and education group $k$ ( $k=1$ if person $i$ is a high school dropout, $k=2$ if person $i$ completed only high school, and $k=3$ if person $i$ completed college) from the wage regression described above for estimating the residual wage for each person in sector $j$ in the 1995 Israel Census;

US residual $S D_{j k}$ is the standard deviation of residuals within sector $j$ and education group $k$ from the wage regression described above using the specification in the first column of Table 2 with workers in sector $j$ in the US CPS data;

$\alpha_{j k}$ is a fixed-effect for education group $k$ in sector $j$; and $\varepsilon_{i}$ is the error term. 
The analysis uses a person's residual wage within a sector as a measure of his unobservable skill, and the residual variation in sector $j$ for education group $k$ as a proxy for the return to unobservable skill in sector $j$ and education group $k{ }^{15}$ With the inclusion of fixed-effects for each sector and education group, the direct effect of the residual variance in each sector and education group is not identified. Therefore, the main coefficients of interest are $\beta_{3}$, and $\beta_{4}$. According to the model, a lower (higher) relative return to skill in Israel versus the US will entice workers with higher (lower) residual wages to leave Israel. Formally, this prediction is represented by $\beta_{3}<0$ and $\beta_{4}>0$. The main identifying assumption is that the differences between Israel and the US in the residual variation across cells is not correlated with an unobservable factor which can generate positive or negative selection within each cell.

Table 9 presents the main analysis for selection on unobservable skill when sectors are defined by the twelve industries displayed in Table 3 . The first column of Table 9 includes the interaction of each person's residual wage with the residual variation in his sector in Israel (excluding the interaction with the residual variation in the United States). The results show that the direct effect of a person's residual wage is positive (although not significant) while the quadratic term is very significant and negative. This pattern forms a non-linear relationship between residual wages and the probability of emigrating, as predicted by Proposition 1 and seen in Figure 4. According to our model, this pattern is indicative of the idea that residual wage is composed of two types of unobservable skills - those that are "general" and can be transferable to the target country and those that are "country-specific" to Israel, and therefore, cannot be transferred to another country.

However, the main parameter of interest in Table 9 is the coefficient on the interaction between a person's residual wage and the residual variation in the person's sector and education cell. This coefficient is negative, but not significant in the first column of Table 9. Similarly, when we include the interaction term for the residual variation in the US, the main parameter is not significant. However, when we include the residual variation in both Israel and the US together in the specification, the interaction terms are much larger in magnitude and marginally significant. Moreover, the signs of the coefficients are consistent with the model - a higher return to unobservable skill in Israel induces individuals with high levels of unobservable skill to stay, while higher returns to unobservable skill in the US increase the chances for individuals with higher levels of unobservable skill to leave

\footnotetext{
${ }^{15}$ There are likely to be differences across education groups within a given sector in the returns to unobservable skills, so the regression explicitly considers this possibility.
} 
Israel.

The fact that the coefficients of interest are smaller in magnitude and significance when one of the interactions is deleted is indicative that individuals compare the relative returns to skill across countries, rather than just looking at the return to skill in their own country. This idea is explicitly modeled in the last column of Table 9 which interacts a person's residual wage with the difference in the returns to unobservable skill between Israel and the US. The interaction term in this specification is highly significant and negative: the probability of emigrating for Israelis with higher levels of unobservable skill declines in sectors with a higher relative return to unobservable skill in Israel versus the US. This result is consistent with Proposition 3.

Table 10 presents the main results for selection on unobservable skill after defining sectors according to occupations. Overall, the pattern of results for the main parameters of interest (the interaction terms) is very similar to the industry-level analysis in Table 9 . In fact, the magnitudes and significance levels are higher than Table 9, and the sign of the coefficients once again are consistent with Proposition 3.

Therefore, in contrast to the results regarding the selection of emigrants in terms of education levels, the results are very similar in terms of selection on unobservable skill in the industry and occupation level analyses. Again, one possible explanation for this could be that occupation is already a proxy for education, so this is likely to affect the results for selection on education levels in a way that does not affect selection on unobservables (since residuals are computed after controlling for occupation and education).

We now examine the sensitivity of the results to different sample selection criteria and to different ways of defining a "mover." Table 11 presents the results for three different sample selection criteria. Although the magnitudes are similar for natives and non-natives (actually a little bigger for the non-natives), the results are statistically significant only for the natives. In the last column of Table 11, we show that the results are similar even after deleting sectors with a small sample size from the regression (less than 1,000 observations). Therefore, the results are not coming from small sectors with influential outliers.

Table 12 presents results for different ways of defining a "mover." The first two columns compare the results obtained using "mover" status as of 2004 to "mover" status as of 2002. The results are a little weaker and less significant, but are generally similar using both definitions. The third column defines a "mover" as someone who is defined as a "mover" in both 2002 and 2004, and the results are still very similar. The last column defines a mover as someone who is categorized as a "mover" in 2004, but also has been 
out of the country since the end of 2000. Again, the parameters of interest are significant, and indicate that the results are robust to confining the status of "mover" only to those who have been out of the country for several years.

\section{A Few More Robustness Checks}

Tables 13 and 14 present a few more robustness checks for the selection on education and unobservable skill. The first column in Table 13 replicates the benchmark results used in previous tables. The second column uses the same specifications, but uses a linear probability model (OLS) instead of a probit. The coefficient estimates tend to be considerably stronger and more significant with OLS. The third column estimates the selection of unobservables, but includes an additional regressor for the interaction between the difference in residual variation (Israel versus the US) within a person's sector and the square of his residual wage. Previous specifications only included the interaction with his residual wage, not his residual wage squared. The coefficients on the interaction with the residual squared are not significant, and the main interaction remains similar in size and significance. The last column in Table 13 uses an individual's residual rank within his age group (30-34, 35-39, and 40-45) instead of his actual residual wage in the analysis, since the variance of residual wages tends to increase with age (see Lemieux (2006)). However, the results using ranks instead of levels are still very similar.

In Table 14, we specify a regression which tests for selection on observable skill (education) and unobservable skill (residual wages) in the same regression. Up to now, we estimated them separately in different regressions, since the analysis for observables required using a fixed-effect for sector only, while the analysis for unobservables requires a fixed-effect for each sector and education cell. Therefore, it is not appropriate to estimate them together with fixed-effects for cells defined by sector or sector-education cells. ${ }^{16}$ However, despite these concerns, we now estimate the selection on observable and unobservable skills in the same regression - using fixed-effects for the sector only and then using fixed-effects for the sector-education cell. Table 13 presents these results for both the industry and occupation level analysis. Overall, the results are very similar to all of the previous estimates - a lower relative return to skill increases the level of positive selection

\footnotetext{
${ }^{16}$ Using a fixed-effect for each sector and education cell when we test for selection on education means we would be testing for selection on education within very small ranges of education, and therefore, we believe this is not the appropriate specification. Furthermore, including a fixed-effect for sector only in the analysis on unobservable skill is not entirely appropriate since the person's residual wage is interacted with the return to skill within cells defined by sector and education group, not just sector.
} 
in unobservable skill for both the industry and occupation level analyses, while the results for observable skill are significant only for the industry level analysis. Essentially, the coefficient estimates are unchanged from the analysis that estimates each type of selection separately, and they are robust to whether the fixed-effect is at the sector level or whether they are defined by sector-education cells.

\section{The Magnitude of the Coefficients}

So far, we found statistically significant evidence in favor of increased positive selection on observable and unobservable skill in sectors with a low relative return to skill in Israel versus the US. However, the magnitudes of the coefficients are not easy to interpret from the results presented in the tables. Therefore, we now use our estimates to present the relationship between levels of skill and the propensity to emigrate under several scenarios. Specifically, we compute the predicted values of the regression after substituting different relative returns to skill between Israel and the US, and show how the relationship between skill and the probability of emigration changes under each scenario.

For example, Figure 7 analyzes the magnitude of selection on education from the industry analysis, by showing the predicted levels of emigration (according to the estimated parameters in the last column of Table 5) under various relative differences in the returns to education between Israel and the US. To be precise, the line for "relative return $=-0.04$ " is computed by predicting the probability of emigrating for each person using the coefficients in Table 5, after we substitute -0.04 into the equation in place of the actual relative return to education in Israel versus the US. Then, the predicted probabilities are graphed as a smoothed quadratic function of education in the figure. Figure 7 computes similar lines for other magnitudes for the relative return to education $(-0.02,0.0$, and 0.02$)$. We chose these numbers in order to examine the sensitivity of the relationship between education and emigration using various levels of returns to skill that are similar to the actual levels - Table 2 showed that the aggregate relative return to education in Israel versus the US is roughly -0.03 (0.071 for Israel and 0.10 for the US).

The simulations in Figure 7 show that the relationship between education and the probability of emigrating is very sensitive to the relative return to education. The probability that a person with a college degree (15 years of schooling) emigrates doubles when the relative return decreases in Israel from -0.02 to -0.04. In the other direction, when the relative return moves in the positive direction (i.e. higher returns in Israel), the relation- 
ship between education and emigration becomes negative (which is easier to see in Figure 8). In Figure 9, we compare the predicted emigration rates using the actual relative return to education with the predicted rates after decreasing the actual relative return by 0.02 . Again, this change in the relative return exacerbates the positive selection significantly. In Figure 10, we compare the actual rates with what happens when the relative return to education in Israel is increased by 0.03 (which roughly makes the average return equal in Israel and the US). Overall, Figure 10 shows that the entire relationship between education and emigration can be eliminated if the relative returns to skill were similar to those in the US. These simulations suggest that the estimated selection parameters are not only significant statistically, but are considerably large in magnitude. (We do not do simulations for the occupation-level analysis of selection on education, since these coefficients were not significant, and therefore, the magnitudes should be considered close to zero.)

In order to demonstrate the magnitude of selection on unobservable skill, Figure 11 shows the predicted emigration rates from the industry level analysis for various levels of the relative return to unobserved skill between Israel and the US. For example, the line for "relative residual SD $=-0.05$ " is computed by predicting the probability of emigrating for each person using the coefficients in Table 9, after we substitute -0.05 into the equation in place of the actual difference in residual variation between Israel and the US. We do the same for other values of the relative difference in residual variation, and the predicted probabilities are graphed as a smoothed quadratic function of the residual wage decile in the figure.

Figure 11 demonstrates that the inverse U-shaped pattern between residual wages and emigration rates shifts to the right as the relative return to skill in Israel versus the US decreases. Consistent with Proposition 3, the tendency for individuals with higher levels of unobserved skill to leave the country increases as the return to unobserved ability declines in Israel. When the relative return declines from 0.05 to -0.05 , the emigration rate of those at the second lowest decile declines from about 1.70 percent to 1.40 percent, while the rate for those at the second highest decile increases from 1.35 percent to 1.55 percent. This shift in the propensity to emigrate is consistent with the idea that country-specific skills keep the overall pattern of the relationship in the form of an inverse U-shape, while the increase in the return to general unobservable skills induces a shift rightward in the entire curve.

Figure 12 compares the actual rates of emigration to those predicted by the model when the relative level of residual variation is decreased by 0.04. Again, we see the shift 
rightward of the entire curve: the emigration rate of those at the second lowest decile decreases from 1.55 to 1.45 percent, while the rate at the second highest decile increases from 1.40 to 1.50 percent. These are reasonably large shifts in terms of the magnitudes, but Figure 13 shows that if we essentially equalize the residual variation between Israel and the US displayed in Table 2 (by increasing the relative difference by 0.025 ), the shift in the curve is not very large. Therefore, we draw two conclusions from these figures. First, the coefficient for the selection on unobservables in the industry-level analysis is quite significant in magnitude. However, the relative difference in residual variation between the US and Israel is not very large.

A similar set of figures is now presented for the selection of unobservable skill using the occupation level analysis. Figure 14 shows the familiar shift to the right of the Ushaped curve when the relative return to unobservable skill decreases in Israel versus the US, thus increasing positive selection on unobservable skill. However, the magnitudes are larger than those depicted in Figure 11 for the industry level analysis, which follows from the larger coefficient for the interaction parameter in Table 10 (-0.055) versus -0.031 in Table 9. The larger magnitudes are displayed again in Figure 15 which shows a large shift towards greater positive selection when the relative return in Israel is decreased by 0.04 , and in Figure 16 which shows a significant decrease in positive selection when the relative return in Israel increases by 0.025 (essentially equalizing the residual variation across the two countries). Overall, these figures show that the parameters governing the selection process on unobservable skill are significant statistically and also in magnitude.

Furthermore, the simulations in this section confirm the main predictions of the model: a decrease in the relative return to education in Israel increases the positive relationship between education and the propensity to emigrate, while the U-shaped relationship between unobservable skill and emigration shifts to the right when the relative return to unobserved skill in Israel declines.

\section{Conclusion}

Using a unique data set containing information on the labor market outcomes of individuals before they decide to move or not, this paper presents the most extensive analysis of emigrant selection based on observable and unobservable skills. Building on the theoretical framework of Roy (1951) and Borjas (1987, 1991, 1999), we develop a model which predicts that the relationship between education and emigration should be positive if the relative 
return to education is lower in the source country versus a potential host country, while the relationship between moving and unobservable skills should be characterized by an inverse U-shaped pattern. The first prediction is similar to Borjas (1987), since education is considered a general skill in our analysis. However, unobservable skills are composed of both general and country-specific skills, and since those at the top of the income distribution are the most likely to have both types of skill in abundance, they are less likely to risk losing their country-specific skills by moving than those towards the middle of the unobservable skill distribution. Thus, the pattern for unobservable skills exhibits an inverse U-shape.

These predictions are supported by the general patterns in our data. Furthermore, we exploit differences across sectors in the relative returns to observable and unobservable skills between Israel and the United States to identify the causal effect of inequality in each country on the propensity to emigrate. We find strong evidence that a lower return to unobservable skills in Israel versus the United States entices higher ability Israelis to leave the country. Also, we find that the positive relationship between education and the probability of moving intensifies in industries with a lower relative return to education in Israel versus the United States. The estimates suggest that the positive relationship between education and emigration could be eliminated entirely if the returns to skill were similar across the two countries.

It is worthwhile to note that these results are unlikely to be due to US immigration policy. Although US immigration authorities do consider the skill level and sector of work for each Israeli applying for a visa, the regressions control for sector-specific effects (industry and occupation), and it is highly unlikely that US immigration authorities are running regressions within each sector in the US and Israel, and tailoring their policies to the relative returns within each sector between the US and a small country like Israel. Overall, the results strongly support our model and the importance of differentiating between general and "country-specific" skills in the analysis of immigrant selection.

Our findings have important implications regarding the desired level of inequality in a country. Although the high level of inequality in the United States is commonly regarded in a negative light, it does play an important role in making the United States a magnet for the most talented workers in the world. Therefore, to a large degree, a country's level of inequality represents how well it will be able to compete with the US for its smartest people. So, even if a country has a high level of inequality, like Israel, it should be careful about reducing it in ways that will lead to a significant brain drain. 


\section{APPENDIX}

We now present the proofs to the proposition in the main text.

PROOF OF PROPOSITION 1:

1. For $a-\beta e>0$, if $\tilde{w}<1$, then $g^{\sim} U[0, \tilde{w})$. Since $g \leq \tilde{w}$, for $\tilde{w} \leq \frac{a-\beta e+\tilde{w}}{1+\gamma} \longleftrightarrow$ $\tilde{w} \leq \frac{a-\beta e}{\gamma}$, then $p(\tilde{w}, e)=0$. For $\tilde{w} \in\left(\frac{a-\beta e}{\gamma}, 1\right)$, as follows from equation $(4), p(\tilde{w}, e)=$ $\frac{\tilde{w}-\frac{a-\beta e+\tilde{w}}{1+\gamma}}{\tilde{w}}=\frac{\gamma}{1+\gamma}-\frac{a-\beta e}{(1+\gamma) \tilde{w}}$. If $\tilde{w} \geq 1$, then $g^{\sim} U[\tilde{w}-1,1]$. For $\frac{a-\beta e+\tilde{w}}{1+\gamma} \geq 1 \longleftrightarrow \tilde{w} \geq$ $1+\gamma-(a-\beta e), p(\tilde{w}, e)=0$. For $\tilde{w} \in(1,1+\gamma-(a-\beta e))$, as follows from (4), noting that since $\gamma<1$ and $\tilde{w} \leq 2, \frac{a-\beta e+\tilde{w}}{1+\gamma}>\tilde{w}-1, p(\tilde{w}, e)=\frac{1-\frac{a-\beta e+\tilde{w}}{1+\gamma}}{1-(\tilde{w}-1)}=\frac{1+\gamma-(a-\beta e)-\tilde{w}}{(2-\tilde{w})(1+\gamma)}$.

Parts 2-7 follow from the properties of (5).

\section{PROOF OF PROPOSITION 2:}

The proposition follows directly from the properties of (5), noting that $\beta>0$.

\section{PROOF OF PROPOSITION 3:}

For any given $\tilde{w}$ and $e$, there exists a threshold level of $g$ above which individuals decide to emigrate. In particular, for $\tilde{w}=1$, it follows that $g^{\sim} U[0,1]$, and hence this threshold level of $g$ is represented by $\hat{g}(1 ; e)=1-p(1 ; e)=1-\frac{\gamma-(a-\beta e)}{\gamma+1}=\frac{1+(a-\beta e)}{\gamma+1}$. Since $s+g=\tilde{w}$, it follows that an individual at the threshold level of $g$, given that $\tilde{w}=1$, will have specific skills equal to $s=1-\hat{g}=\frac{\gamma-(a-\beta e)}{\gamma+1}$. For this individual, by definition of being at the threshold, $w_{0}=w_{1}$, and hence $\beta e+\gamma g=a+s$. Suppose there is a rise in $\gamma$ and $a$ such that this individual remains indifferent, and hence, $p(1, e)$ is unchanged. In this case, the rise in $a$ is given by $d a=g d \gamma=\frac{1+(a-\beta e)}{\gamma+1} d \gamma$, where $d \gamma$ is the change in $\gamma$.

For $\tilde{w} \in\left(\frac{a-\beta e}{\gamma}, 1\right), p(\tilde{w}, e)=\frac{\gamma}{\gamma+1}-\frac{a-\beta e}{(1+\gamma) \tilde{w}}$. Therefore, the change in $p(\tilde{w}, e), d p(\tilde{w}, e)$, holding $p(1, e)$ constant, is

$$
d p(\tilde{w}, e)=\left(\frac{\gamma+d \gamma}{\gamma+d \gamma+1}-\frac{a+d a-\beta e}{(1+\gamma+d \gamma) \tilde{w}}\right)-\left(\frac{\gamma}{\gamma+1}-\frac{a-\beta e}{(1+\gamma) \tilde{w}}\right) .
$$

Replacing $d a$ by $\frac{1+(a-\beta e)}{\gamma+1} d \gamma$,

$$
d p(\tilde{w}, e)=\left(\frac{\gamma+d \gamma}{\gamma+d \gamma+1}-\frac{a+\frac{1+(a-\beta e)}{\gamma+1} d \gamma-\beta e}{(1+\gamma+d \gamma) \tilde{w}}\right)-\left(\frac{\gamma}{\gamma+1}-\frac{a-\beta e}{(1+\gamma) \tilde{w}}\right)
$$

and re-arranging:

$$
d p(\tilde{w}, e)=\frac{1}{\tilde{w}} \frac{d \gamma}{\gamma+1} \frac{\tilde{w}-1}{\gamma+d \gamma+1} .
$$

Hence, for $d \gamma>0$ and $\tilde{w}<1, d p(\tilde{w}, e)<0$. 
Similarly, for $\tilde{w} \in(1,1+\gamma-(a-\beta e)), p(\tilde{w}, e)=\frac{1+\gamma-(a-\beta e)-\tilde{w}}{(2-\tilde{w})(1+\gamma)}$, and the change in $p(\tilde{w}, e), d p(\tilde{w}, e)$, holding $p(1, e)$ constant is,

$$
d p(\tilde{w}, e)=\frac{1+\gamma+d \gamma-(a+d a-\beta e)-\tilde{w}}{(2-\tilde{w})(1+\gamma+d \gamma)}-\frac{1+\gamma-(a-\beta e)-\tilde{w}}{(2-\tilde{w})(1+\gamma)}
$$

replacing $d a$ by $\frac{1+(a-\beta e)}{\gamma+1} d \gamma$,

$$
d p(\tilde{w}, e)=\frac{1+\gamma+d \gamma-\left(a+\frac{1+(a-\beta e)}{\gamma+1} d \gamma-\beta e\right)-\tilde{w}}{(2-\tilde{w})(1+\gamma+d \gamma)}-\frac{1+\gamma-(a-\beta e)-\tilde{w}}{(2-\tilde{w})(1+\gamma)},
$$

and re-arranging:

$$
d p(\tilde{w}, e)=\frac{d \gamma}{\gamma+1} \frac{1-\tilde{w}}{(\tilde{w}-2)(\gamma+d \gamma+1)} .
$$

Hence, for $d \gamma>0$ and $\tilde{w}>1, d p(\tilde{w}, e)>0$.

\section{PROOF OF PROPOSITION 4:}

First note that the density function derived from the distribution of $\tilde{w}$, which is the sum of two independent uniform distributions on the unit interval, is:

$$
f(\tilde{w})=\left\{\begin{array}{ccc}
\tilde{w} & \text { for } & \tilde{w} \leq 1 \\
2-\tilde{w} & \text { for } & \tilde{w}>1
\end{array}\right.
$$

Hence, it follows from Proposition 1 that

$$
\begin{aligned}
p(e) & =\int_{0}^{2} p(\tilde{w}, e) f(\tilde{w}) d \tilde{w} \\
& =\int_{\frac{a-\beta e}{\gamma}\left(\frac{\gamma}{\gamma+1}-\frac{a-\beta e}{(1+\gamma) \tilde{w}}\right) f(\tilde{w}) d \tilde{w}+\int_{1}^{1+\gamma-(a-\beta e)}\left(\frac{1+\gamma-(a-\beta e)-\tilde{w}}{(2-\tilde{w})(1+\gamma)}\right) f(\tilde{w}) d \tilde{w}} \\
& =\frac{1}{2 \gamma(\gamma+1)}(\gamma-a+\beta e)^{2}+\frac{1}{2(\gamma+1)}(\gamma-a+\beta e)^{2} \\
& =(\gamma-a+\beta e)^{2}\left(\frac{1}{2 \gamma(\gamma+1)}+\frac{1}{2(\gamma+1)}\right) \\
& =\frac{(\gamma-a+\beta e)^{2}}{2 \gamma}
\end{aligned}
$$

the derivatives appearing in the proposition are straightforward noting that $\gamma>a$. 


\section{References}

[1] Ben-David, Dan. "Brain Drained: A Tale of Two Countries," CEPR Working Paper 6717, February 2008.

[2] Belot, Michele and Timothy J. Hatton. "Immigrant Selection in the OECD," CEPR Working Paper 6675, February 2008.

[3] Borjas, George J. 1987. "Self-Selection and the Earnings of Immigrants." American Economic Review 77 (4), September 1987, 531-553.

[4] Borjas, George J. 1991. "Immigration and Self-Selection." in Immigration, Trade, and the Labor Market, edited by John M. Abowd and Richard B. Freeman. Chicago: University of Chicago Press (for NBER).

[5] Borjas, George J. 1999. "The Economic Analysis of Immigration." in Handbook of Labor Economics, vol.3A, edited by Orley Ashenfelter and David Card. Amsterdam: North-Holland.

[6] Borjas, George J., Stephen G. Bronars, and Stephen J. Trejo. 1992. "Self-Selection and Internal Migration in the United States." Journal of Urban Economics 32 (September): $159-85$.

[7] Brandolini, Andrea and Timothy M. Smeeding. "Inequality: International Evidence," New Palgrave Dictionary of Economics, forthcoming 2008.

[8] Chiswick, Barry (1999). "Are Immigrants Favorably self-selected?" American Economic Review - Papers and Proceedings, 89, 2: 181-85.

[9] Chiquiar, Daniel and Gordon Hanson, "International Migration, Self-Selection, and the Distribution of Wages: Evidence from Mexico and the United States," Journal of Political Economy, 113(2), 2005, 239-281.

[10] Cobb-Clark, Deborah A. "Immigrant Selectivity and Wages: The Evidence for Women," American Economic Review, 83 (4), September 1993, 986-993.

[11] Feliciano, C. (2005), "Educational Selectivity in U.S. Immigration: How do Immigrants Compare to Those Left Behind?" Demography, 42, 131-152.

[12] Gould, Eric and Omer Moav. "Israel's Brain Drain," Israel Economic Review, 5 (1), November 2007, 1-22.

[13] Grogger, Jeffrey and Gordon H. Hanson. "Income Maximization and the Selection and Sorting of International Migrants," NBER Working Paper 13821, February 2008.

[14] Ibarraran, Pablo and Darren Lubotsky. "Mexican Immigration and Self-Selection: New Evidence from the 2000 Mexican Census," NBER Working Paper No 11456 , June 2005.

[15] Juhn C., K. M. Murphy, and B. Pierce. "Wage Inequality and the Rise in Returns to Skill," Journal of Political Economy, 101, 1993, 410-442.

[16] Lemieux, Thomas. "Increasing Residual Wage Inequality: Composition Effects, Noisy Data, or Rising Demand for Skill?" American Economic Review, 2006, 1-64. 
[17] McKenzie, David and Hillel Rapoport. (2007). "Self-Selection Patterns in Mexico-U.S. Migration: The Role of Migration Networks." World Bank Policy Research Working Paper 4118.

[18] Mountford, A. (1997), "Can a Brain Drain be Good for Growth in the Source Economy?" Journal of Development Economics, 53, pp. 287-303.

[19] Orrenius, Pia M. and Madeline Zavodny, "Self-Selection Among Undocumented Immigrants From Mexico," Journal of Development Economics, 78, 2005, 215-240.

[20] Rosenzweig, Mark R. (2006), "Global Wage Differences and International Student Flows," In S. M. Collins and C. Graham (eds.), Brookings Trade Forum, 2006: Global Labor Markets, Washington D.C: Brookings Institution Press.

[21] Roy, Andrew D. (1951), "Some Thoughts on the Distribution of Earnings," Oxford Economic Papers, 3 (June 1951), 135-146.

[22] Sjaastad, Larry A. (1962). "The Costs and Returns of Human Migration, Journal of Political Economy, Vol. 70, 5, Part 2: Investment in Human Beings. (October, 1962), 80-93. 
Table 1: Descriptive Statistics for Male Workers from the 1995 Israel Census

\begin{tabular}{lccc} 
& Mean & Standard Deviation \\
\cline { 2 - 2 } Mover 2004 & & \\
Mover 2002 & 0.016 & 0.126 \\
Returned 2002-2004 (for Movers 2002) & 0.013 & 0.114 \\
Left by end of 2000 (for Movers 2004) & 0.020 & 0.141 \\
Education & 13.011 & 0.470 \\
Age & 37.773 & 3.187 \\
Married & 0.898 & 4.613 \\
Native & 0.614 & 0.303 \\
Age Arrived in Israel (non-natives only) & 20.344 & 0.487 \\
Asia-Africa Origin & 0.466 & 0.499 \\
European Origin & 0.480 & 0.500 \\
Israeli Origin & 0.054 & \\
Number of Children & 2.130 & \\
Log Wage (monthly) & 8.605 & \\
Observations & & \\
\cline { 2 - 3 }
\end{tabular}

The core sample used throughout the paper and in this table includes all male respondents between the ages of 30 and 45 in the 1995 Israel Census who were not self-employed, worked at least 30 hours a week, and worked at least six months in the previous 12 months. Wages are monthly wages in Israeli Shekels using 1995 prices. 


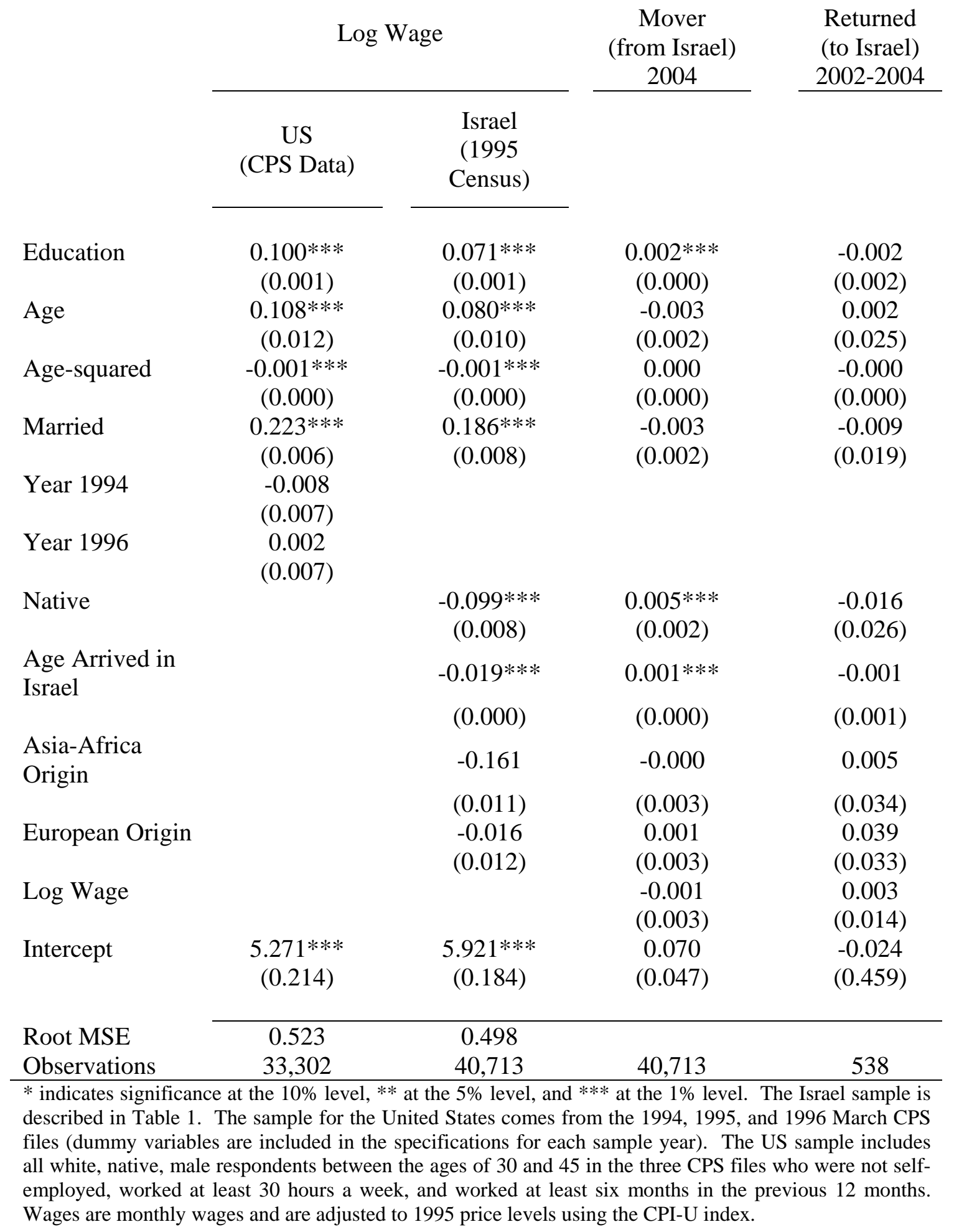




\begin{tabular}{|c|c|c|c|c|c|c|}
\hline $\begin{array}{c}\text { Mean } \\
\text { Mover } \\
2004\end{array}$ & $\begin{array}{l}\text { Mean } \\
\text { Log } \\
\text { Wage }\end{array}$ & $\begin{array}{l}\text { Mean } \\
\text { Educa- } \\
\text { tion }\end{array}$ & $\begin{array}{l}\text { ROR to } \\
\text { Educ in } \\
\text { Israel }\end{array}$ & $\begin{array}{l}\text { ROR to } \\
\text { Educ in } \\
\text { US }\end{array}$ & $\begin{array}{l}\text { Residual } \\
\text { SD in } \\
\text { Israel }\end{array}$ & $\begin{array}{c}\text { Residual } \\
\text { SD in } \\
\text { US }\end{array}$ \\
\hline
\end{tabular}

\begin{tabular}{|c|c|c|c|c|c|c|c|c|}
\hline $\begin{array}{l}\text { Agriculture, } \\
\text { Forestry, } \\
\text { Fishing }\end{array}$ & 663 & 0.015 & 8.199 & 11.157 & 0.039 & 0.070 & 0.488 & 0.525 \\
\hline Mfg & 13493 & 0.017 & 8.561 & 12.723 & 0.078 & 0.113 & 0.451 & 0.500 \\
\hline Electric, Water & 1038 & 0.014 & 8.821 & 13.163 & 0.058 & 0.079 & 0.418 & 0.407 \\
\hline Construction & 2939 & 0.020 & 8.463 & 11.939 & 0.064 & 0.091 & 0.479 & 0.543 \\
\hline $\begin{array}{l}\text { Wholesale and } \\
\text { Retail }\end{array}$ & 6270 & 0.014 & 8.533 & 12.341 & 0.072 & 0.094 & 0.513 & 0.535 \\
\hline $\begin{array}{l}\text { Trans., Storage, } \\
\text { Comm. }\end{array}$ & 3331 & 0.011 & 8.610 & 12.036 & 0.072 & 0.088 & 0.510 & 0.531 \\
\hline $\begin{array}{l}\text { Bank, Finance, } \\
\text { Insurance }\end{array}$ & 1627 & 0.010 & 8.996 & 14.286 & 0.068 & 0.108 & 0.467 & 0.496 \\
\hline $\begin{array}{l}\text { Real Estate, } \\
\text { Business }\end{array}$ & 3776 & 0.022 & 8.784 & 14.871 & 0.069 & 0.124 & 0.533 & 0.535 \\
\hline Public Admin. & 3216 & 0.008 & 8.685 & 12.801 & 0.067 & 0.067 & 0.417 & 0.439 \\
\hline Education & 1488 & 0.018 & 8.578 & 15.545 & 0.052 & 0.073 & 0.484 & 0.440 \\
\hline $\begin{array}{l}\text { Health, } \\
\text { Welfare, Social } \\
\text { Work }\end{array}$ & 1693 & 0.028 & 8.674 & 15.282 & 0.073 & 0.122 & 0.605 & 0.543 \\
\hline Social Service & 1179 & 0.015 & 8.467 & 12.602 & 0.061 & 0.066 & 0.531 & 0.567 \\
\hline
\end{tabular}

Industry categories were matched across the Israeli 1995 Census and the CPS files from the US. The rate of return to education in each sector in Israel comes from a regression specified in the second column of Table 2, but run on a sample of workers within each sector. The "Residual SD" for each sector in Israel comes from the same set of regressions and is computed by calculating the standard deviation of residuals within each education group (high school dropouts, high school graduates, and college graduates) within each sector, and then computing the mean by sector. Similarly, the returns to education and "Residual SD" for the US comes from similar regressions as specified in the first column in Table 1 for each sector. 
Table 4: Occupation Descriptive Statistics of the Israeli Sample with US CPS Variables

\begin{tabular}{|c|c|c|c|c|c|c|c|c|}
\hline & $\mathrm{N}$ & $\begin{array}{l}\text { Mean } \\
\text { Mover } \\
2004\end{array}$ & $\begin{array}{l}\text { Mean } \\
\text { Log } \\
\text { Wage }\end{array}$ & $\begin{array}{l}\text { Mean } \\
\text { Educa- } \\
\text { tion }\end{array}$ & $\begin{array}{l}\text { ROR to } \\
\text { Educ in } \\
\text { Israel }\end{array}$ & $\begin{array}{l}\text { ROR to } \\
\text { Educ in } \\
\text { US }\end{array}$ & $\begin{array}{l}\text { Residual } \\
\text { SD in } \\
\text { Israel }\end{array}$ & $\begin{array}{l}\text { Residual } \\
\text { SD in US }\end{array}$ \\
\hline $\begin{array}{l}\text { Academic } \\
\text { Professionals }\end{array}$ & 5624 & 0.027 & 8.945 & 16.842 & 0.016 & 0.067 & 0.516 & 0.489 \\
\hline $\begin{array}{l}\text { Associate } \\
\text { Professionals } \\
\text { and } \\
\text { Technicians }\end{array}$ & 3867 & 0.018 & 8.723 & 14.044 & 0.041 & 0.070 & 0.467 & 0.475 \\
\hline Managers & 4452 & 0.012 & 9.139 & 14.371 & 0.047 & 0.098 & 0.511 & 0.507 \\
\hline Clerical & 4395 & 0.008 & 8.610 & 12.764 & 0.063 & 0.054 & 0.452 & 0.521 \\
\hline $\begin{array}{l}\text { Agents, Sales, } \\
\text { and Service }\end{array}$ & 4429 & 0.012 & 8.496 & 12.183 & 0.054 & 0.113 & 0.489 & 0.571 \\
\hline $\begin{array}{l}\text { Skilled } \\
\text { Agricultural }\end{array}$ & 516 & 0.016 & 8.152 & 11.258 & 0.036 & 0.060 & 0.462 & 0.529 \\
\hline $\begin{array}{l}\text { Skilled } \\
\text { Workers }\end{array}$ & 13835 & 0.017 & 8.379 & 11.472 & 0.045 & 0.070 & 0.438 & 0.509 \\
\hline $\begin{array}{l}\text { Unskilled } \\
\text { Workers }\end{array}$ & 3595 & 0.014 & 8.348 & 11.717 & 0.063 & 0.054 & 0.473 & 0.532 \\
\hline
\end{tabular}


Table 5: Selection on Education - Main Results for the Industry Level Analysis

Probit for being a Mover in 2004

Education*

Israel ROR Educ in Industry i

Education*

US ROR Educ in Industry i

Education*

Diff between Israel and US in

ROR Educ in Industry $\mathrm{i}$

Industry Wage Residual

Industry Wage Residual $^{2}$

Education

Married

Number of Children

Native

Age Arrived in Israel

Industry Fixed Effects

Observations

$$
-0.0146
$$

(0.018)

$$
\begin{gathered}
-0.0930 * * * \\
(0.027)
\end{gathered}
$$

$$
\begin{array}{cc}
0.0202 * * & 0.0511 * * * \\
(0.0083) & (0.012)
\end{array}
$$

$-0.0427 * * *$

(0.011)

* indicates significance at the $10 \%$ level, $* *$ at the $5 \%$ level, and *** at the $1 \%$ level. All specifications include controls for age, age-squared, and ethnic dummies.. Coefficients are the marginal effects calculated at the sample means of the explanatory variables. 
Table 6: Selection on Education - Main Results for the Occupation Level Analysis

Probit for being a Mover in 2004

Education*

Israel ROR Educ in Occup i

$-0.0297 * *$
$(0.012)$

$-0.0298 * *$

(0.012)

Education*

US ROR Educ in Occup i

$\begin{array}{cc}-0.0221 * * & -0.0219 * * \\ (0.010) & (0.0099)\end{array}$

Education*

0.00157

Diff between Israel and US in

(0.0079)

ROR Educ in Occupation i

Occupation Wage Residual

$\begin{array}{cccc}-0.000909 & -0.000868 & -0.000871 & -0.000895 \\ (0.0011) & (0.0011) & (0.0011) & (0.0011) \\ -0.00482^{* * *} & -0.00480^{* * *} & -0.00484^{* * *} & -0.00478^{* * *} \\ (0.0015) & (0.0015) & (0.0015) & (0.0015) \\ 0.00240^{* * *} & 0.00269^{* * *} & 0.00400^{* * *} & 0.00113^{* * *} \\ (0.00058) & (0.00075) & (0.00093) & (0.00029) \\ 0.00115 & 0.00110 & 0.00117 & 0.00109 \\ (0.0014) & (0.0014) & (0.0014) & (0.0015) \\ -0.00200^{* * *} & -0.00197^{* * *} & -0.00201 * * * & -0.00196 * * * \\ (0.00045) & (0.00045) & (0.00045) & (0.00045) \\ 0.00262 & 0.00255 & 0.00262 & 0.00255 \\ (0.0017) & (0.0017) & (0.0017) & (0.0017) \\ 0.000646 * * * & 0.000635 * * & 0.000644 * * * & 0.000637 * * * \\ (0.000062) & (0.000062) & (0.000062) & (0.000062) \\ & & & \\ \text { Yes } & \text { Yes } & \text { Yes } & \text { Yes } \\ 40,713 & 40,713 & 40,713 & 40,713\end{array}$

Occupation Fixed Effects

40,713

40,713

40,713

40,713

* indicates significance at the $10 \%$ level, ${ }^{* *}$ at the $5 \%$ level, and $* * *$ at the $1 \%$ level. All specifications include controls for age, age-squared, and ethnic dummies.. Coefficients are the marginal effects calculated at the sample means of the explanatory variables. 
Table 7: Selection on Education - Sensitivity to Sample Selection

Probit for being a Mover in 2004

Industry Level Analysis

Education*

Diff between Israel and US

$-0.0427 * * * \quad-0.0484 * * *$

$-0.0321$

$-0.0426 * * *$

(0.011)

(0.012)

(0.024)

$(0.011)$

in ROR Educ in Industry $\mathrm{i}$

Sample Restriction

None

Natives

Non-Natives

Industries

with Sample

Size $>1000$

Industry Fixed Effects

Yes

Yes

Yes

Yes

Observations

40,713

25,011

15,702

40,050

\section{Occupation Level Analysis}

Education*

Diff between Israel and US

in ROR Educ in Occupation i

Sample Restriction

None

Natives

Non-Natives

Occupations
with Sample
Size $>1000$

Occupation Fixed Effects

Yes

Yes

Yes

Yes

Observations

* indicates significance at the $10 \%$ level, $* *$ at the $5 \%$ level, and *** at the $1 \%$ level. All specifications include controls for education, age, age-squared, ethnic dummies, marital status, native status, and age arrived in Israel (if non-native). The industry analysis also controls for the individual's residual wage within his industry and its square, while the occupation analysis controls for the individual's residual wage within his occupation and its square. Coefficients are the marginal effects calculated at the sample means of the explanatory variables. 
Table 8: Selection on Education - Sensitivity to Various Definitions of a "Mover"

$\begin{array}{cccc}\text { Mover } 2004 & \begin{array}{c}\text { Mover } \\ 2002\end{array} & \begin{array}{c}\text { Mover } 2002 \\ \text { and } 2004\end{array} & \begin{array}{c}\text { Mover } 2004 \\ \text { since } 2000\end{array}\end{array}$

\section{Industry Level Analysis}

Education*

$$
\begin{array}{cccc}
-0.0427 * * * & -0.0321 * * * & -0.0315 * * * & -0.0269 * * * \\
(0.011) & (0.010) & (0.010) & (0.0090)
\end{array}
$$

Diff between Israel and US in

ROR Educ in Industry i

Industry Fixed Effects

Yes

Yes

Yes

Yes

Observations

40,713

40,713

40,713

40,713

\section{Occupation Level Analysis}

$\begin{array}{lllll}\text { Education* } & 0.00157 & 0.00136 & 0.00151 & -0.00103 \\ \text { Diff between Israel and US in } & (0.0079) & (0.0074) & (0.0073) & (0.0064)\end{array}$

ROR Educ in Occupation i

Occupation Fixed Effects

Yes

Yes

Yes

Yes

Observations

40,713

40,713

40,713

40,713

\footnotetext{
* indicates significance at the $10 \%$ level, $* *$ at the $5 \%$ level, and $* * *$ at the $1 \%$ level. All specifications include controls for education, age, age-squared, ethnic dummies, marital status, native status, and age arrived in Israel (if non-native). The industry analysis also controls for the individual's residual wage within his industry and its square, while the occupation analysis controls for the individual's residual wage within his occupation and its square. Coefficients are the marginal effects calculated at the sample means of the explanatory variables.
} 
Table 9: Selection on Unobservables - Main Industry Level Analysis

Probit for being a Mover in 2004

Industry Wage Residual*

Israel Residual SD

in Industry-Education Group i

Industry Wage Residual*

US Residual SD

in Industry-Education Group i

Industry Wage Residual *

Difference between Israel and

US in Residual SD

in Industry-Education Group i

Industry Wage Residual

Industry Wage Residual $^{2}$

Education

Married

Number of Children

Native

Age Arrived in Israel

Industry-Education Group

Fixed Effects

$$
\begin{array}{r}
-0.0212 \\
(0.015)
\end{array}
$$

$-0.0295^{*}$

(0.016)
$-0.0311^{* *}$

(0.015)

Observations

* indicates significance at the $10 \%$ level, $* *$ at the $5 \%$ level, and *** at the $1 \%$ level. All specifications include controls for age, age-squared, and ethnic dummies.. Coefficients are the marginal effects calculated at the sample means of the explanatory variables. 
Table 10: Selection on Unobservables - Main Occupation Level Analysis

Probit for being a Mover in 2004

Occupation Wage Residual*

Israel Residual SD

$-0.0764 * * *$

$-0.0785^{* * *}$

(0.028)

$(0.028)$

in Occup-Education Group i

Occupation Wage Residual*

US Residual SD

in Occup-Education Group i

$\begin{array}{ll}0.0245 & 0.0303 \\ (0.029) & (0.029)\end{array}$

Occupation Wage Residual *

$-0.0552 * * *$

Difference between Israel and

$(0.021)$

US in Residual SD

in Occup-Education Group i

Occupation Wage Residual

Occupation Wage Residual ${ }^{2}$

$\begin{array}{cccc}0.0357^{* * *} & -0.0135 & 0.0213 & -0.00257^{* *} \\ (0.014) & (0.015) & (0.019) & (0.0012) \\ -0.00569^{* * *} & -0.00493^{* * *} & -0.00584^{* * *} & -0.00569^{* * *} \\ (0.0015) & (0.0015) & (0.0015) & (0.0015) \\ 0.000897^{* * *} & 0.00088^{* * *} & 0.000896^{* * *} & 0.000892^{* * *} \\ (0.00024) & (0.0003) & (0.00024) & (0.00024) \\ 0.000969 & 0.000999 & 0.000956 & 0.000958 \\ (0.0014) & (0.0014) & (0.0014) & (0.0014) \\ -0.00187^{* * *} & -0.00190^{* * *} & -0.00186^{* * *} & -0.00187^{* * *} \\ (0.00044) & (0.00044) & (0.00044) & (0.00044) \\ 0.00224 & 0.00225 & 0.00222 & 0.00221 \\ (0.0017) & (0.0017) & (0.0017) & (0.0017) \\ 0.000596^{* * *} & 0.00060^{* * *} & 0.000596 * * * & 0.000596 * * * \\ (0.000063) & (0.00006) & (0.000063) & (0.000063) \\ & & & \\ \text { Yes } & \text { Yes } & \text { Yes } & \text { Yes }\end{array}$

Occupation-Education Group

Fixed Effects

\begin{tabular}{lrrrr} 
Observations & 40,621 & 40,621 & 40,621 & 40,621 \\
\hline$*$ indicates significance at the $10 \%$ level, $* *$ at the $5 \%$ level, and *** at the $1 \%$ level. All specifications
\end{tabular}

\begin{tabular}{lrrrr} 
Observations & 40,621 & 40,621 & 40,621 & 40,621 \\
\hline$*$ indicates significance at the $10 \%$ level, $* *$ at the $5 \%$ level, and *** at the $1 \%$ level. All specifications
\end{tabular}

\begin{tabular}{lrrrr} 
Observations & 40,621 & 40,621 & 40,621 & 40,621 \\
\hline$*$ indicates significance at the $10 \%$ level, $* *$ at the $5 \%$ level, and *** at the $1 \%$ level. All specifications
\end{tabular} include controls for age, age-squared, and ethnic dummies.. Coefficients are the marginal effects calculated at the sample means of the explanatory variables. 
Table 11: Selection on Unobservables - Sensitivity to Sample Selection

Probit for being a Mover in 2004

\section{Industry Level Analysis}

Industry Wage Residual *

$\begin{array}{cccc}-0.0311^{* *} & -0.0244 * & -0.0340 & -0.0331^{* *} \\ (0.015) & (0.014) & (0.033) & (0.015)\end{array}$

and US in Residual SD in

(0.015)

Industry-Education Group i

Sample Restriction

-Education Group

Fixed Effects

Observations
None

Natives

Non-Natives

Yes

Yes

Yes

24,674

15,602

40,412

Industries

with Sample

Size $>1000$

(24,674

15,602

39,749

\section{Occupation Level Analysis}

$\begin{array}{lcccc}\text { Occupation Wage Residual * } & -0.0552^{* * *} & -0.0515^{* *} & -0.0636 & -0.0621^{* * *} \\ \text { Difference between Israel } & (0.021) & (0.023) & (0.044) & (0.021)\end{array}$

and US in Residual SD in

Occup-Education Group i

Sample Restriction

None

Natives

Non-Natives

Occupations

with Sample

Size $>1000$

Occupation-Education Group

Yes

Yes

Yes

Yes

Fixed Effects

Observations

40,621

24,573

15,673

40,105

\footnotetext{
* indicates significance at the $10 \%$ level, $* *$ at the $5 \%$ level, and $* * *$ at the $1 \%$ level. All specifications include controls for education, age, age-squared, ethnic dummies, marital status, native status, and age arrived in Israel (if non-native). The industry analysis also controls for the individual's residual wage within his industry and its square, while the occupation analysis controls for the individual's residual wage within his occupation and its square. Coefficients are the marginal effects calculated at the sample means of the explanatory variables.
} 
Table 12: Selection on Unobservables - Sensitivity to Definitions of a "Mover"

Mover $2004 \quad$ Mover Mover 2002 Mover 2004

2002 and 2004 since 2000

\section{Industry Level Analysis}

Industry Wage Residual *

$$
\begin{array}{cccc}
-0.0311^{* *} & -0.0223 & -0.0236^{*} & -0.0226^{*} \\
(0.015) & (0.014) & (0.014) & (0.012)
\end{array}
$$

and US in Residual SD in

Industry-Education Group i

$\begin{array}{lcccc}\begin{array}{l}\text { Industry-Education Group } \\ \text { Fixed Effects }\end{array} & \text { Yes } & \text { Yes } & \text { Yes } & \text { Yes } \\ \text { Observations } & 40,412 & 40,412 & 40,412 & 40,412\end{array}$

\section{Occupation Level Analysis}

$\begin{array}{llll}\text { Occupation Wage Residual * } & -0.0552 * * * & -0.0449 * * & -0.0442 * *\end{array} \quad-0.0406 * *$

Difference between Israel $\quad(0.021) \quad(0.019) \quad(0.019) \quad(0.017)$

and US in Residual SD in

Occup-Education Group i

$\begin{array}{lcccc}\begin{array}{l}\text { Occupation-Education Group } \\ \text { Fixed Effects }\end{array} & \text { Yes } & \text { Yes } & \text { Yes } & \text { Yes } \\ \text { Observations } & 40,621 & 40,621 & 40,621 & 40,621\end{array}$

\footnotetext{
* indicates significance at the $10 \%$ level, ${ }^{* *}$ at the $5 \%$ level, and $* * *$ at the $1 \%$ level. All specifications include controls for education, age, age-squared, ethnic dummies, marital status, native status, and age arrived in Israel (if non-native). The industry analysis also controls for the individual's residual wage within his industry and its square, while the occupation analysis controls for the individual's residual wage within his occupation and its square. Coefficients are the marginal effects calculated at the sample means of the explanatory variables.
} 
Table 13: Various Robustness Checks for Mover 2004 Status

Industry Level Analysis

$\begin{array}{lcccc}\begin{array}{l}\text { Education* } \\ \text { Diff between Israel and US in } \\ \text { ROR Educ in Industry i }\end{array} & \begin{array}{c}-0.0427^{* * *} \\ (0.011)\end{array} & \begin{array}{c}-0.0610^{* * *} \\ (0.015)\end{array} & & \begin{array}{c}-0.0422^{* * *} \\ (0.011)\end{array} \\ & & & & \\ & & & & \\ \begin{array}{l}\text { Industry Wage Residual } \\ \text { (or Residual Rank) }\end{array} & -0.0311^{* *} & -0.0348^{*} & -0.0291^{*} & -0.00422^{*} \\ \text { Difference between Israel } & (0.015) & (0.020) & (0.015) & (0.0025)\end{array}$

and US in Residual SD

Industry Wage Residual Squared*

0.00814

Difference between Israel

$(0.018)$

and US in Residual SD

Occupation Level Analysis

Education*

$0.00157 \quad-0.00429$

0.00209

Diff between Israel and US in

$(0.0079) \quad(0.010)$

(0.0079)

ROR Educ in Occupation i

Occupation Wage Residual

$\begin{array}{lcccc}\text { (or Residual Rank) } * & -0.0552^{* * *} & -0.0677^{* * *} & -0.0528^{* *} & -0.00727^{* *} \\ \text { Difference between Israel } & (0.021) & (0.026) & (0.021) & (0.0032)\end{array}$

and US in Residual SD

Occup Wage Residual Squared*

0.0298

Difference between Israel

(0.029)

and US in Residual SD

Using Residual Ranks within

each 5-year Age Group

No No No $\quad$ Yes

Probit or OLS

Probit

OLS

Probit

Probit

\begin{abstract}
* indicates significance at the $10 \%$ level, ** at the 5\% level, and *** at the $1 \%$ level. Within each panel, each column represents a separate regression. The first column represents the "benchmark" specifications described in earlier tables. Changes to the benchmark specifications are described according to the information provided in the table. Residual ranks were computed within the individual's age group, where the age groups are 30-34, 35-39, and 40-45. Coefficients represent the marginal effects (calculated at the sample means of the explanatory variables if it comes from a probit).
\end{abstract}


Table 14: Estimating Selection on Education and Unobservables Together

Probit for being a Mover in 2004

\begin{tabular}{|c|c|c|c|}
\hline \multicolumn{2}{|c|}{ Industry Analysis } & \multicolumn{2}{|c|}{ Occupation Analysis } \\
\hline $\begin{array}{c}-0.0418 * * * \\
(0.011)\end{array}$ & $\begin{array}{c}-0.0306^{*} \\
(0.017)\end{array}$ & & \\
\hline \multirow[t]{3}{*}{$\begin{array}{c}-0.0308^{* *} \\
(0.015)\end{array}$} & $\begin{array}{c}-0.0303^{* *} \\
(0.015)\end{array}$ & & \\
\hline & & $\begin{array}{l}0.00184 \\
(0.0078)\end{array}$ & $\begin{array}{c}-0.0123 \\
(0.011)\end{array}$ \\
\hline & & $\begin{array}{c}-0.0568 * * * \\
(0.021)\end{array}$ & $\begin{array}{c}-0.0546^{* * *} \\
(0.021)\end{array}$ \\
\hline Yes & No & & \\
\hline \multirow[t]{3}{*}{ No } & Yes & & \\
\hline & & Yes & No \\
\hline & & No & Yes \\
\hline 40,713 & 40,412 & 40,713 & 40,621 \\
\hline
\end{tabular}

Observations include controls for education, age, age-squared, ethnic dummies, marital status, native status, and age arrived in Israel (if non-native). The industry analysis also controls for the individual's residual wage within his industry and its square, while the occupation analysis controls for the individual's residual wage within his occupation and its square. Coefficients are the marginal effects calculated at the sample means of the explanatory variables. 
Figure 1a: Native Israelis Leaving Israel By Education 30 to 45 Year Old Israelis



Figure 1b: Non-Native Israelis Leaving Israel By Education 30 to 45 Year Old Israelis




Figure 2a: Israelis Leaving Israel By Education Level

22 to 29 Year Old Israeli Males

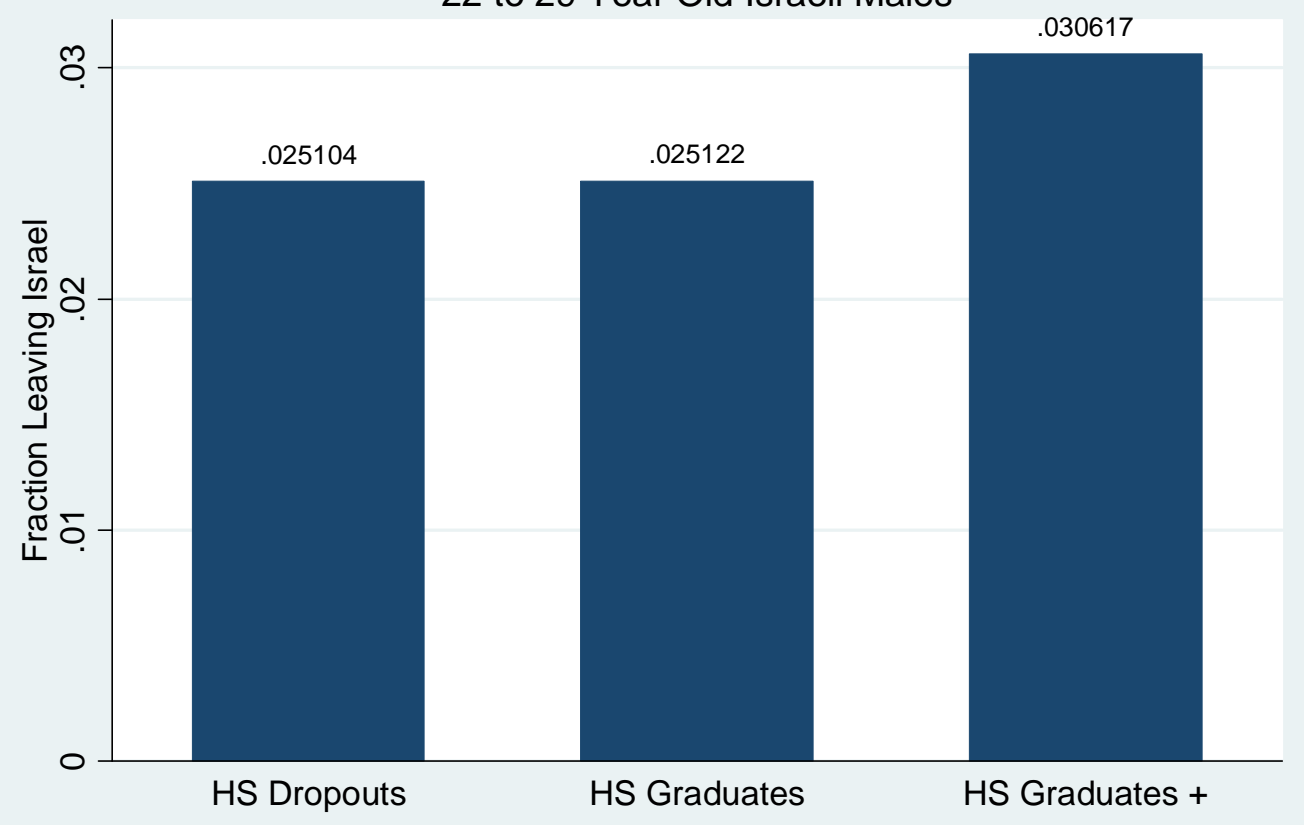

Figure 2b: Israelis Leaving Israel By Father's Education 13 to 17 Year Old Israelis

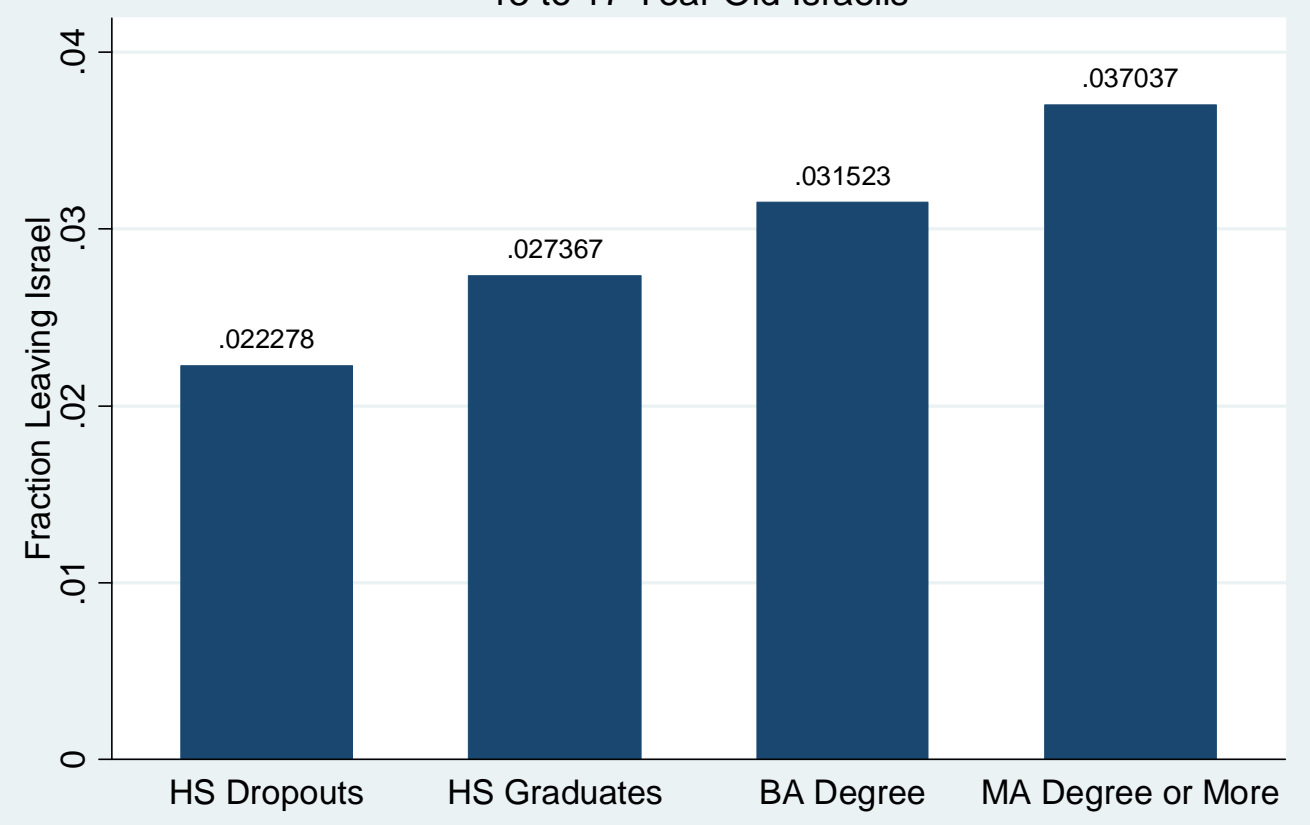


Figure 3: Returning to Israel from 2002-2004 by Education All Israelis Who Were Movers in 2002

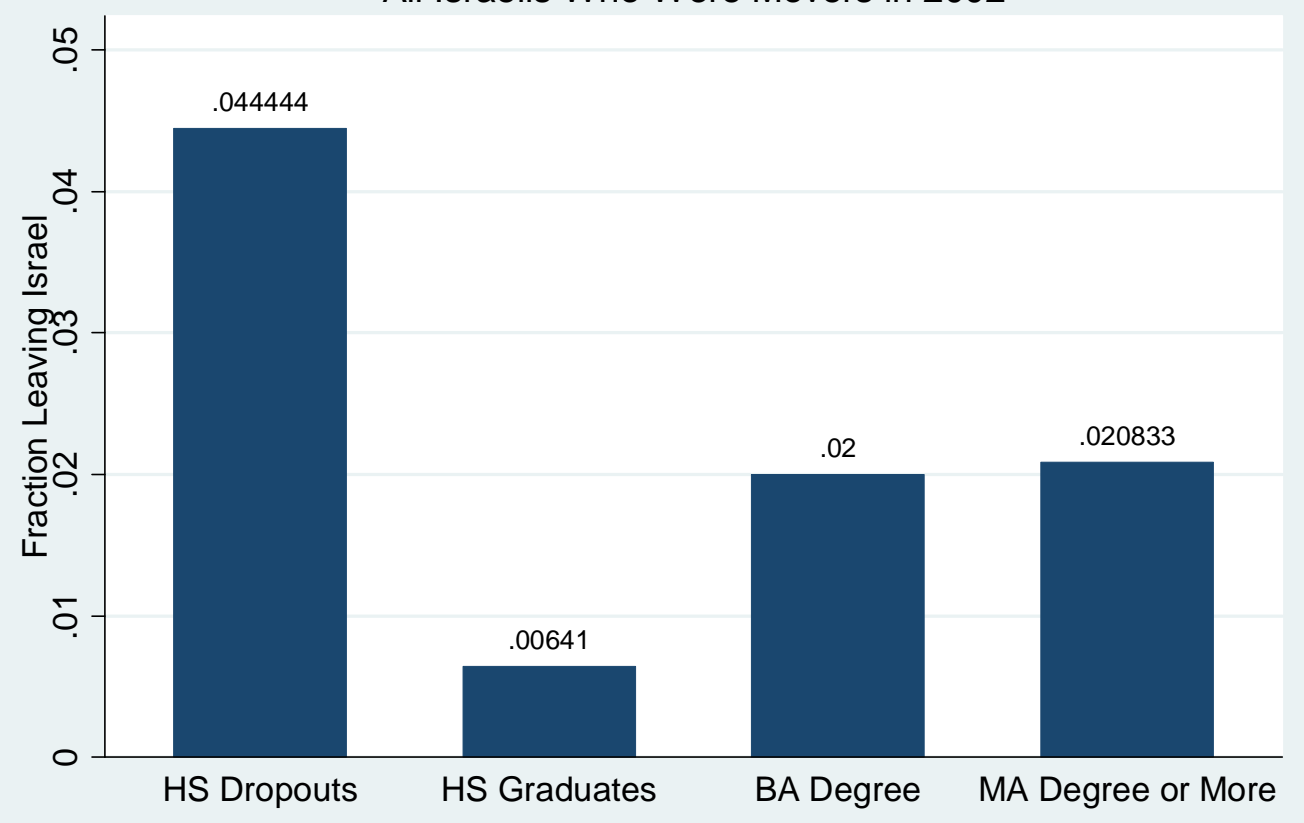

Figure 4: Fraction Leaving Israel by Residual Wages

Controlling for Education, Age, Ethnicity, and Native Status




Figure 5: Fraction Leaving Israel by Residual Wages Controlling for Industry, Education, Age, Ethnicity, and Native Status



Figure 6: Fraction Leaving Israel by Residual Wages

Controlling for Occupation, Education, Age, Ethnicity, and Native Status

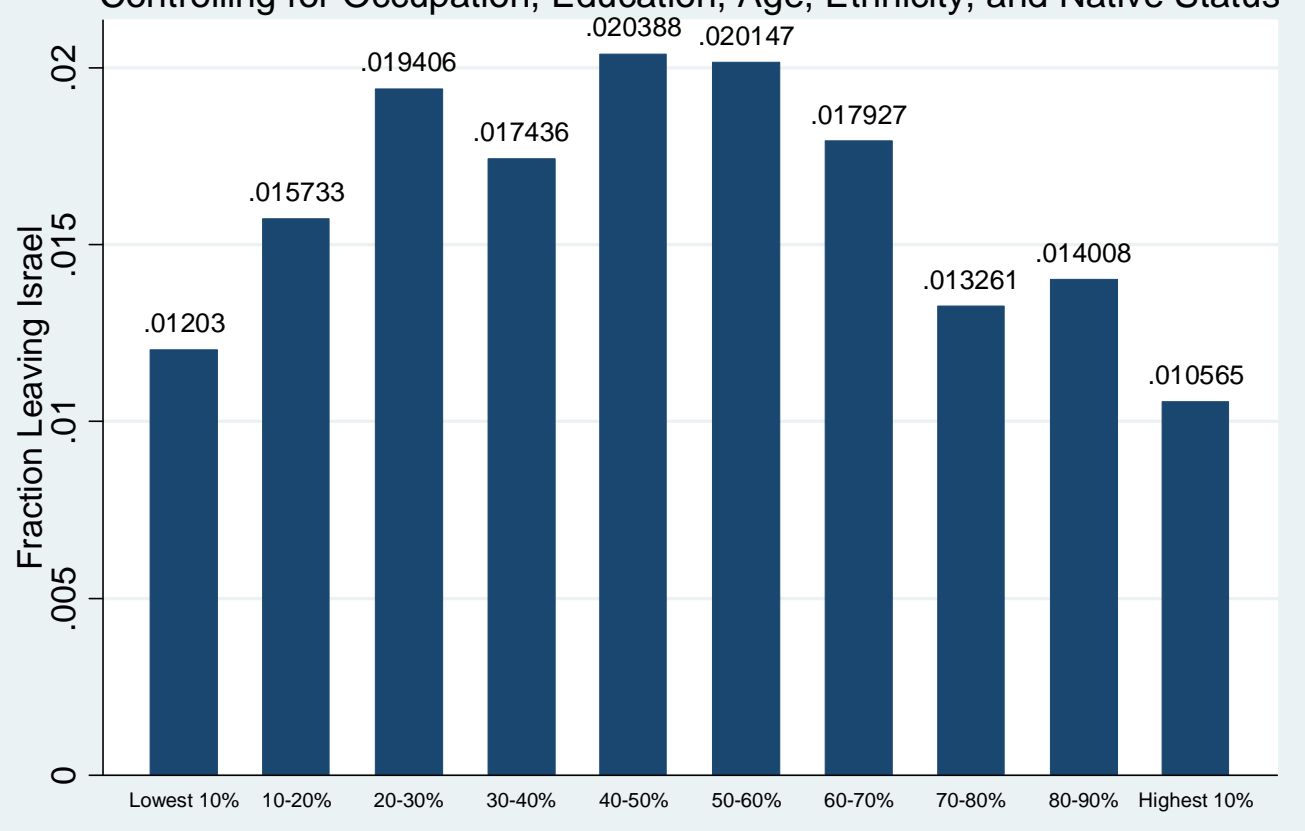




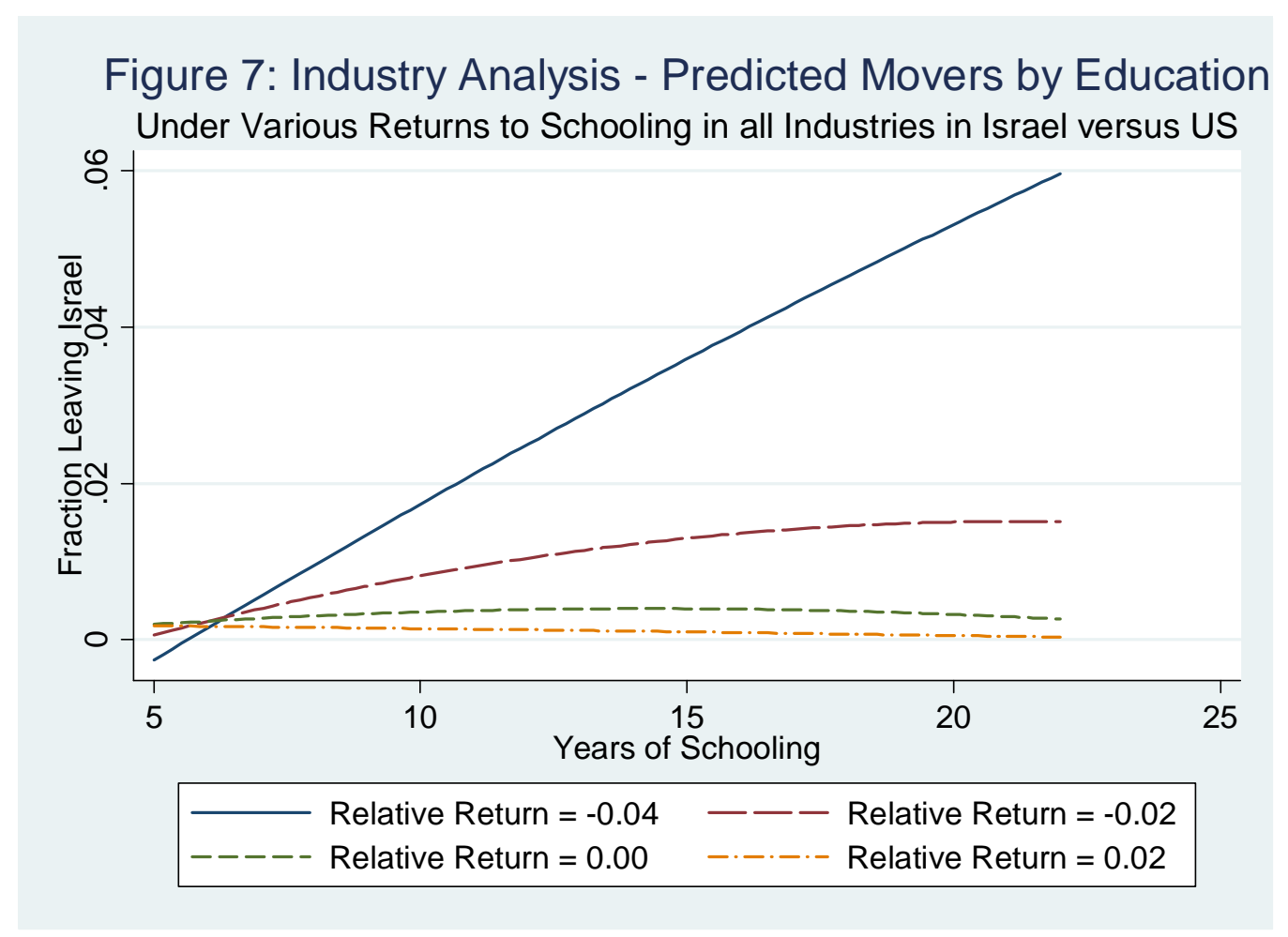

Figure 8: Industry Analysis - Predicted Movers by Education

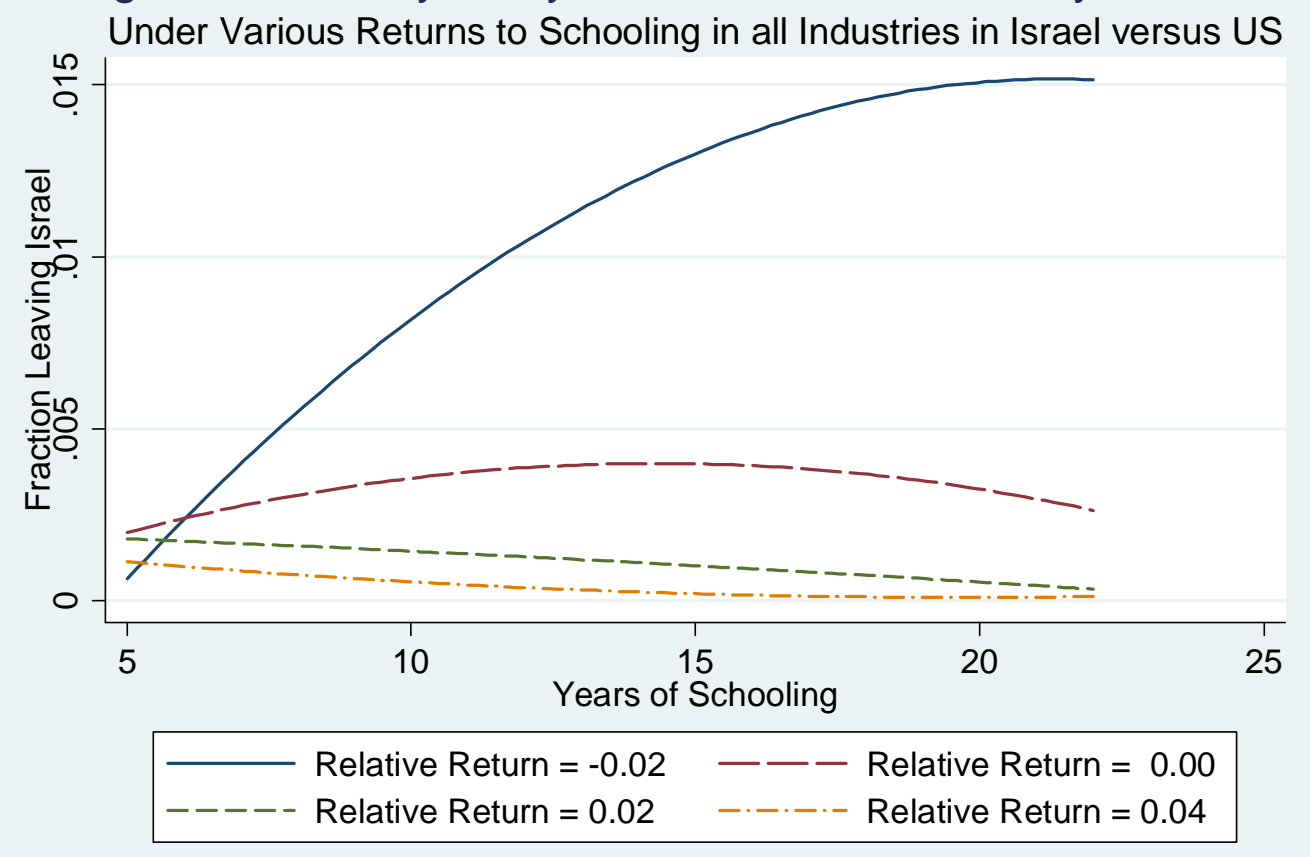


Figure 9: Industry Analysis - Predicted Movers by Education Actual versus Decrease in Relative Return to School in All Industries by 0.02



Figure 10: Industry Analysis - Predicted Movers by Education Actual versus Increase in Relative Return to School in All Industries by 0.03

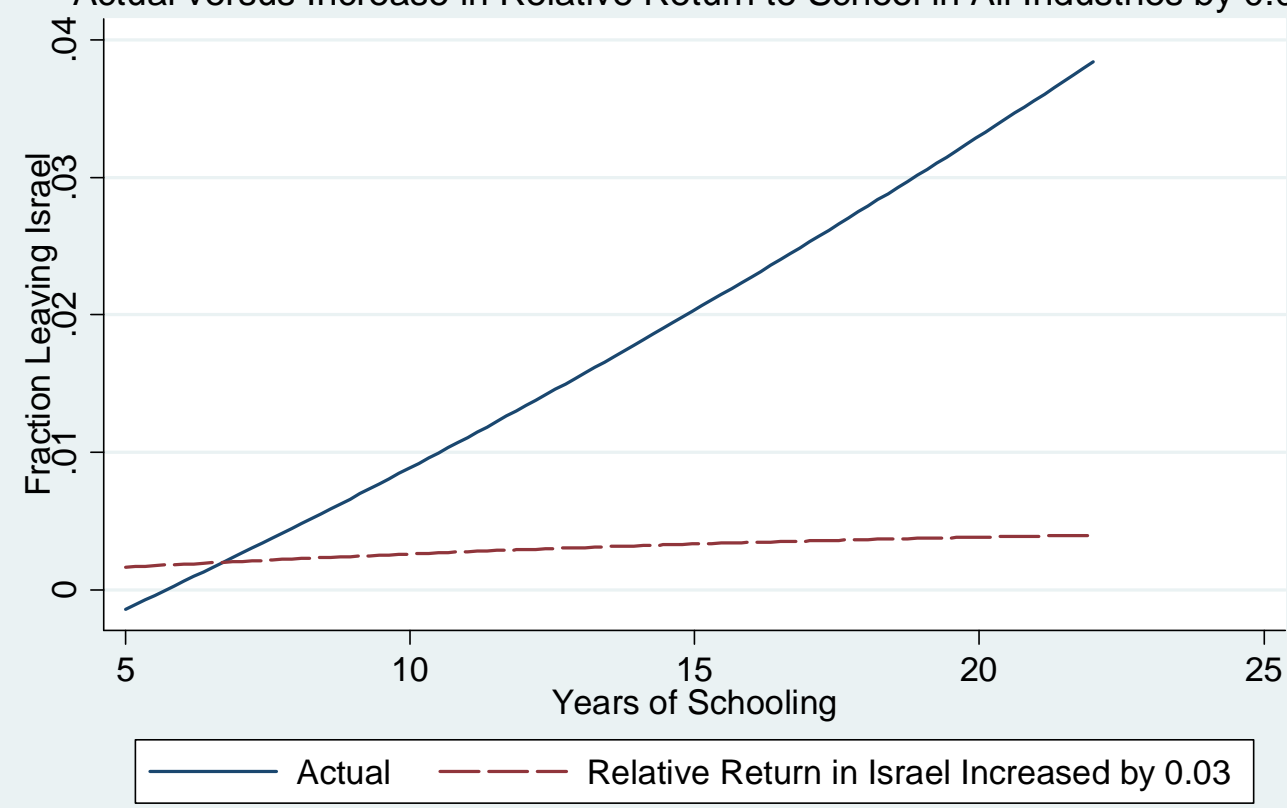




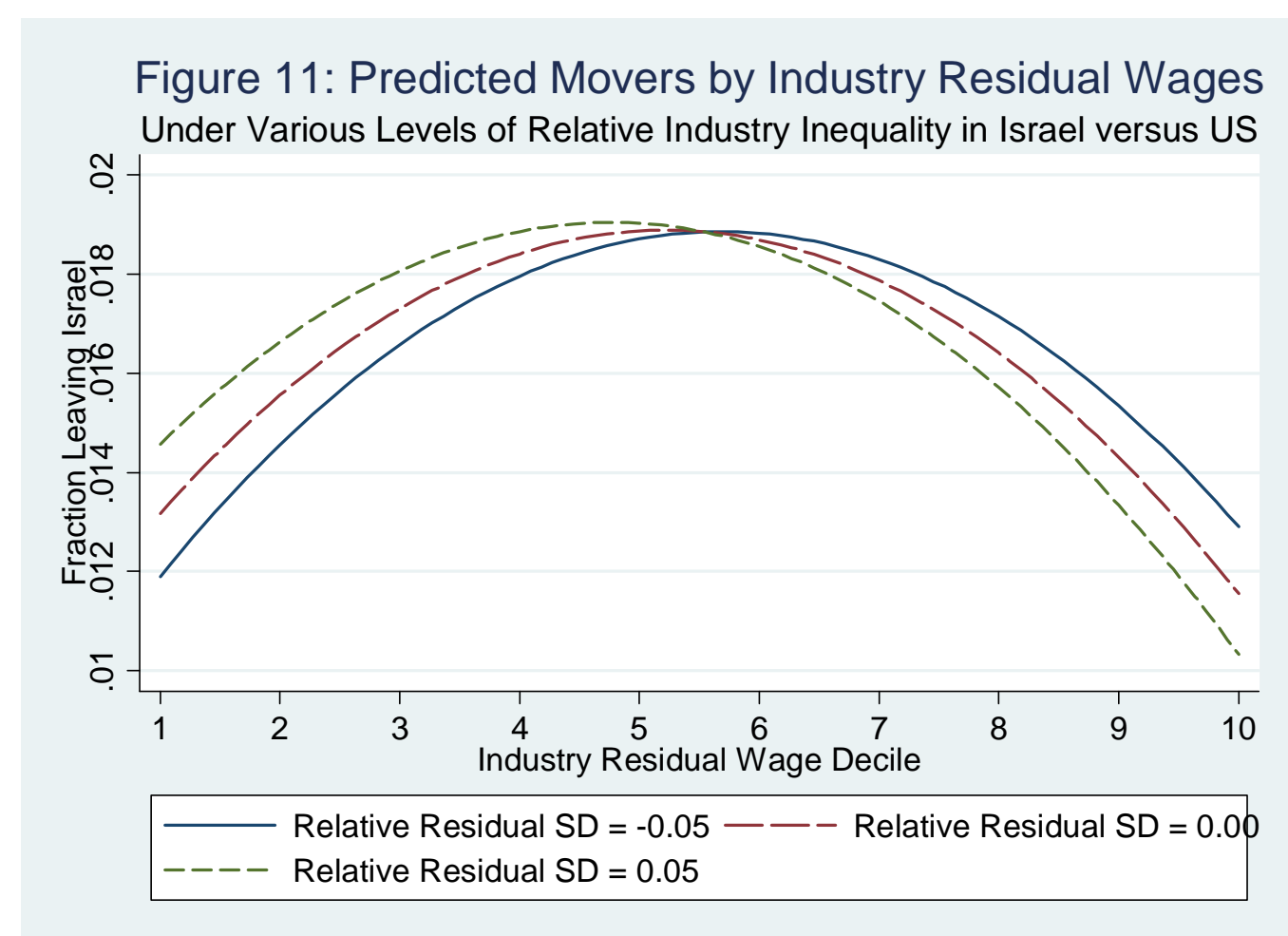

Figure 12: Predicted Movers by Industry Residual Wages Actual versus Decreasing Relative Inequality in all Industries in Israel by 0.04

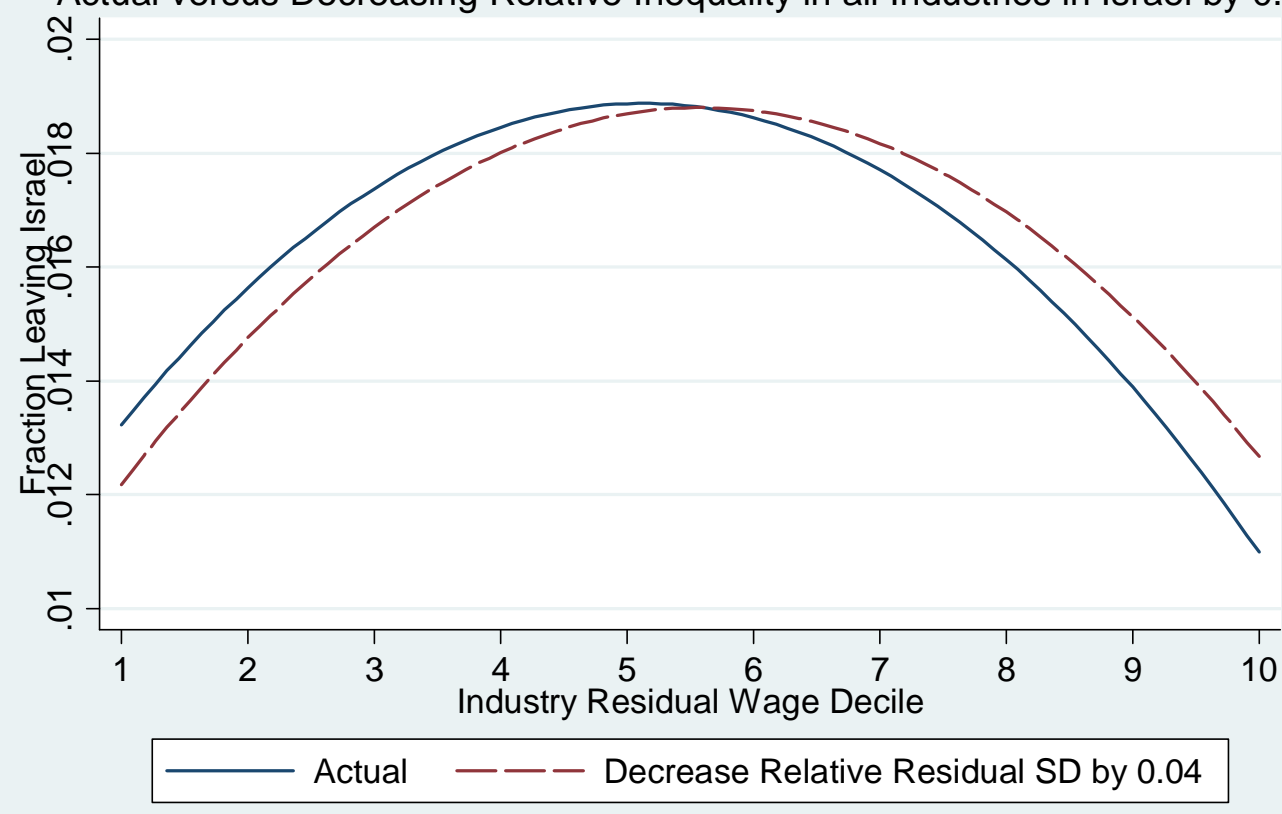


Figure 13: Predicted Movers by Industry Residual Wages Actual versus Increase in Relative Inequality in all Industries in Israel by 0.025

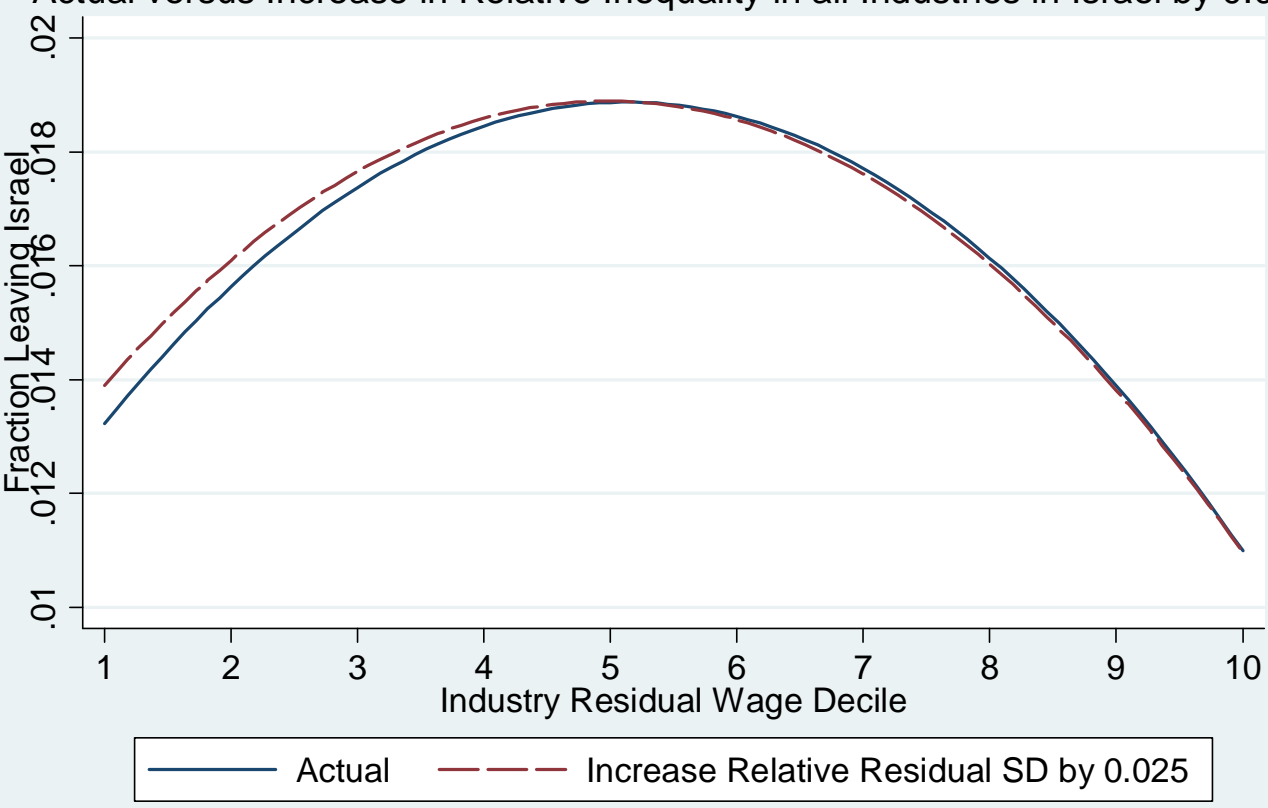

Figure 14: Predicted Movers by Occupation Residual Wages Under Various Levels of Relative Occupation Inequality in Israel versus US

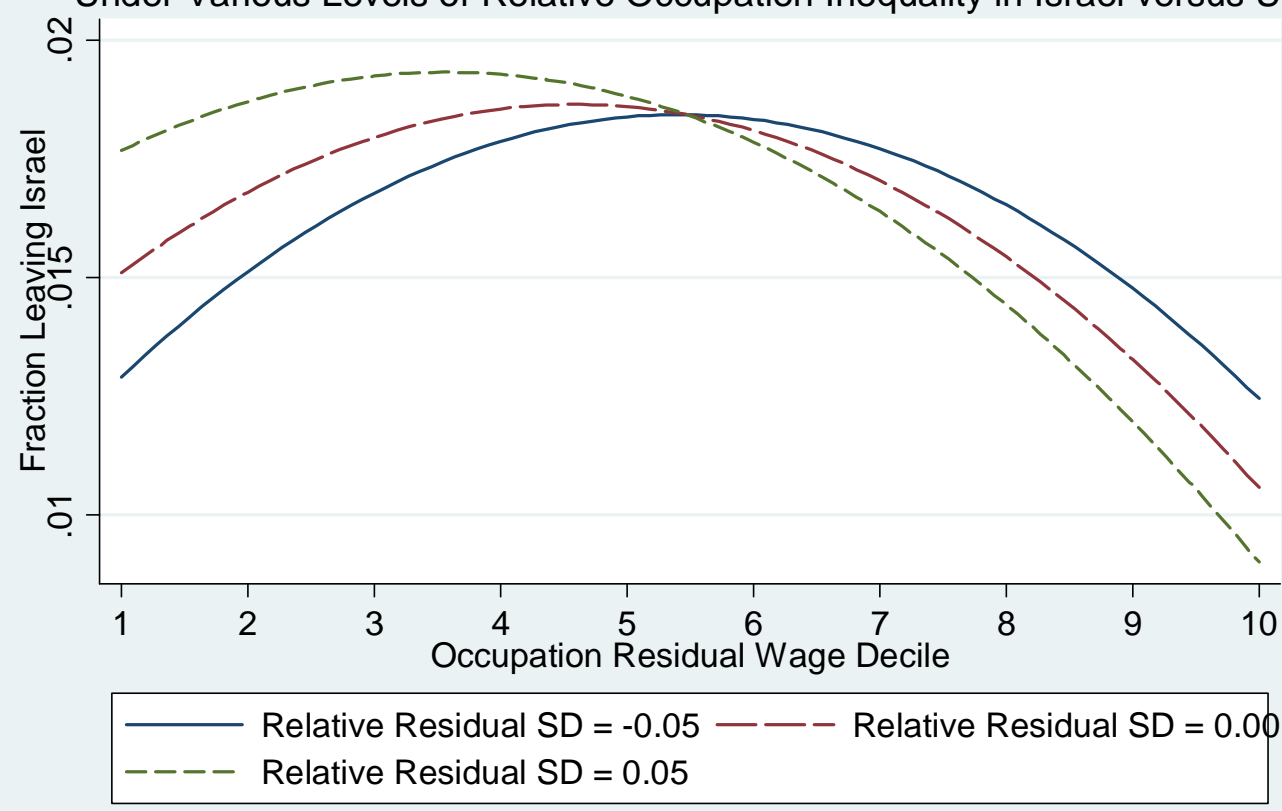


Figure 15: Predicted Movers by Occupation Residual Wages Actual versus Decreasing Relative Inequality in all Occupations in Israel by 0.04

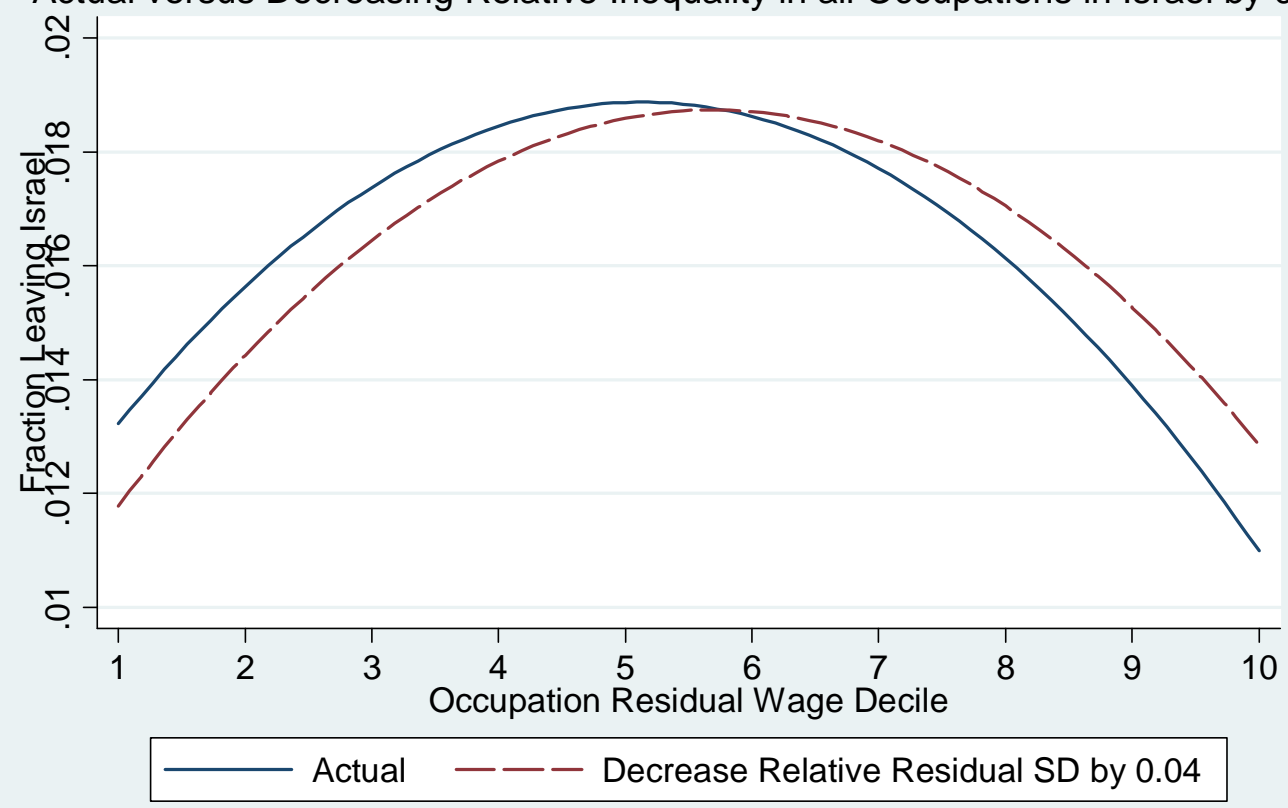

Figure 16: Predicted Movers by Occupation Residual Wages Actual versus Increase in Relative Inequality in all Occupations in Israel by 0.025

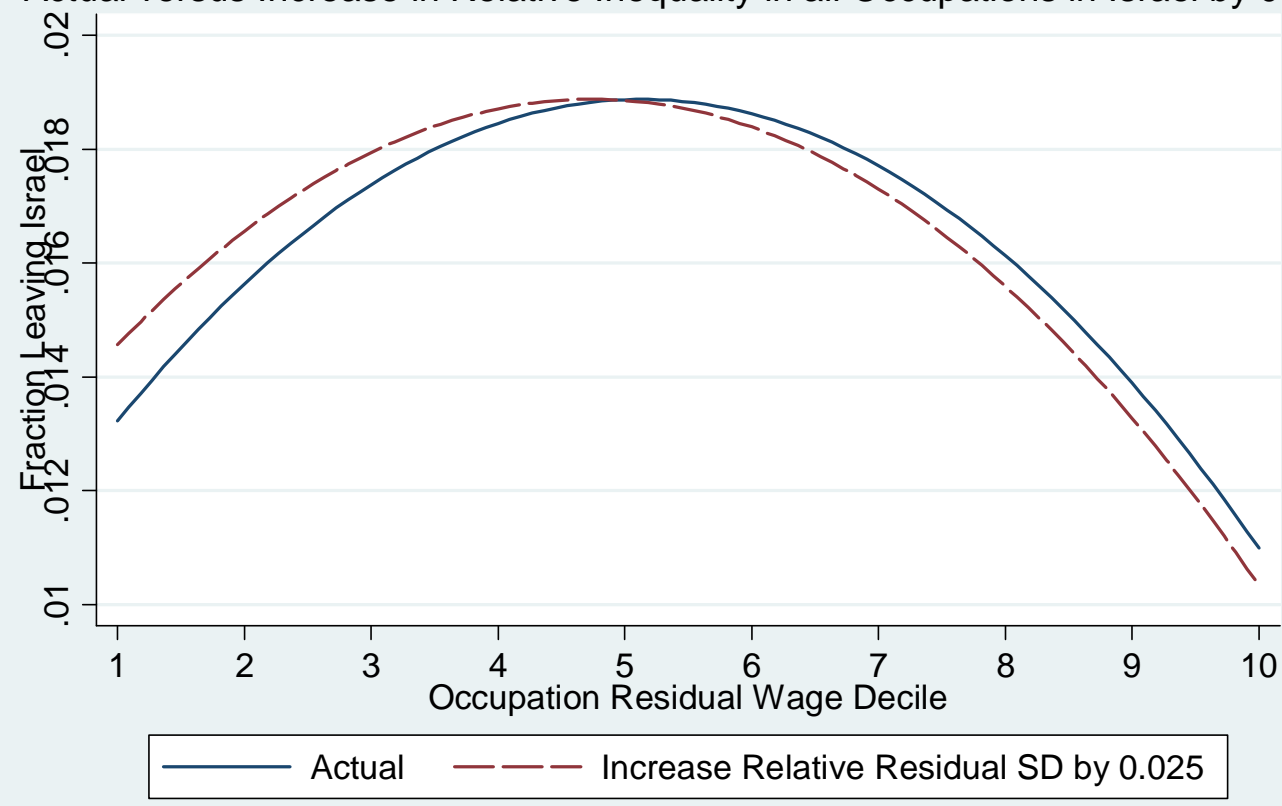

